\title{
Open Source Tech for Scholarly Communication
}

Carly Strasser, PhD

@carlystrasser

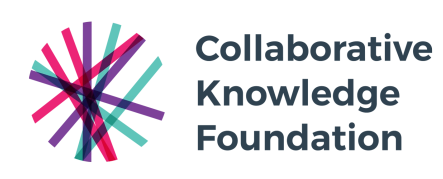




\title{
Scholarly Communication
}

\author{
has issues
}




\section{What is communicated}

\section{When it's communicated}

\section{How it's communicated}

Where the communication goes

Who receives the communication 


\section{What is communicated}

\section{When it's communicated}


The Research Process

\section{Publish results} Analyzé findings Gather information Research \& desigh Ask questions 


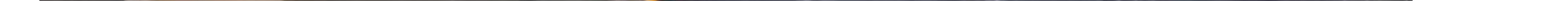




\section{- Toty The Research Process}

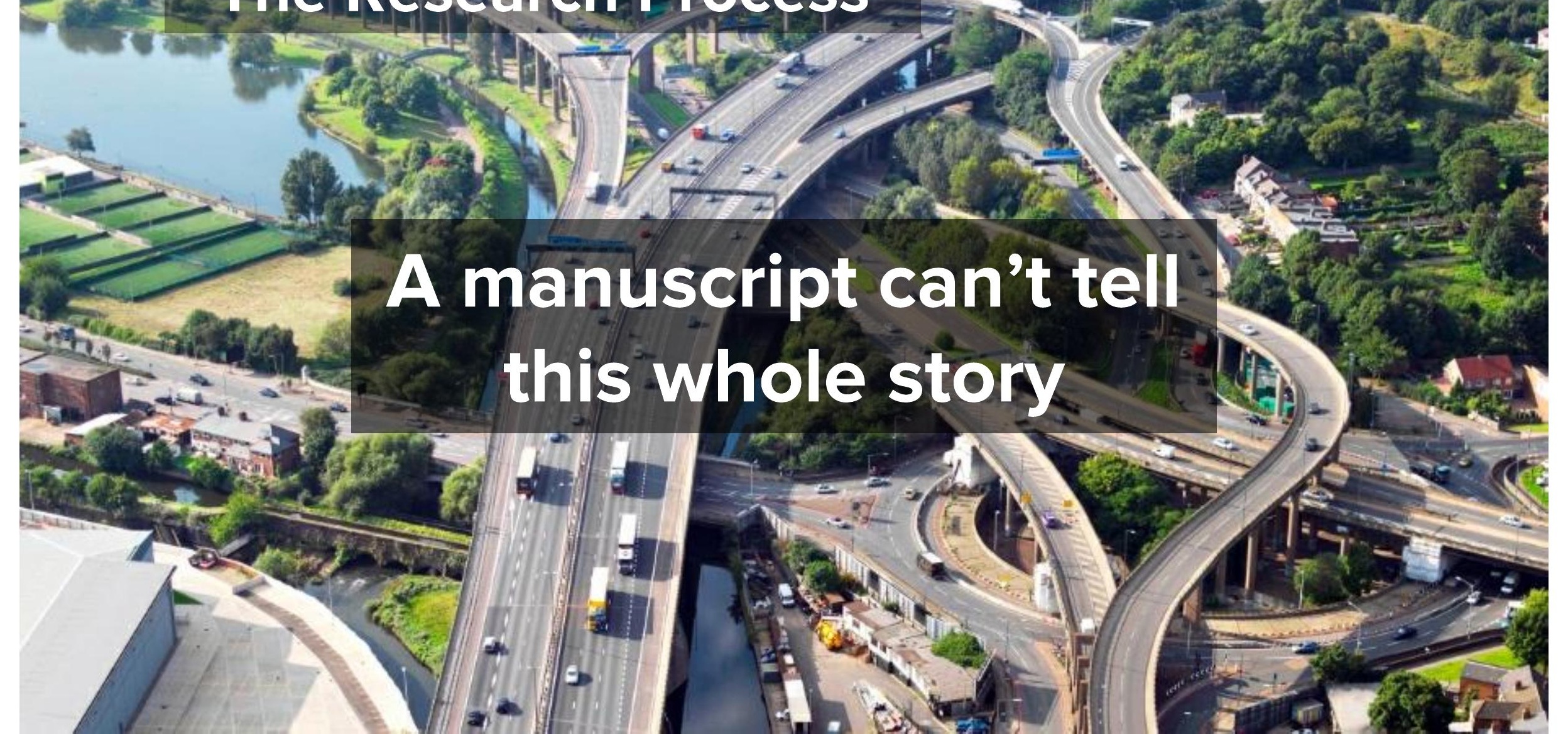




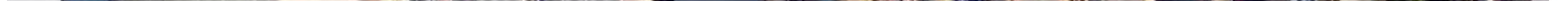




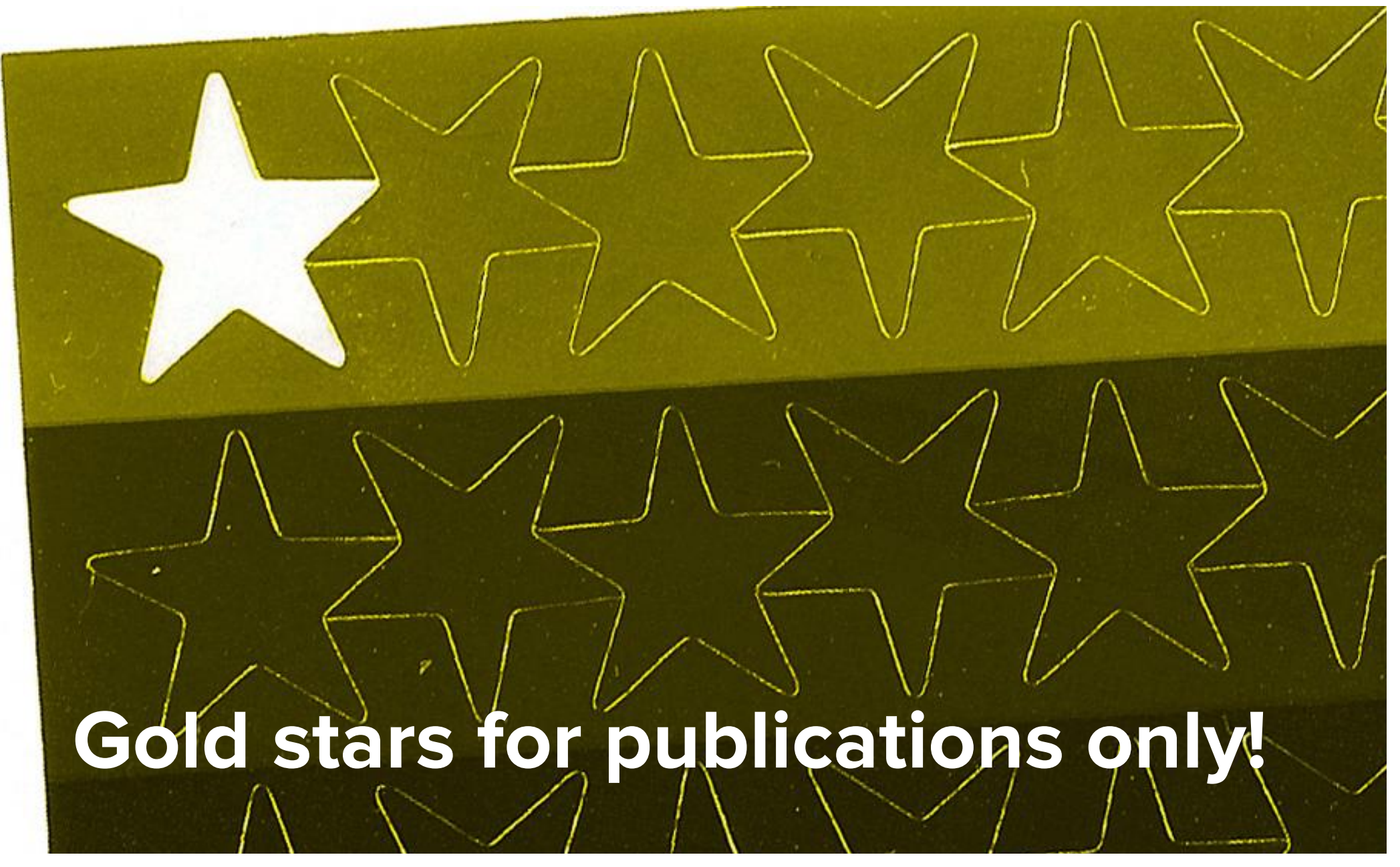




\section{How it's communicated}




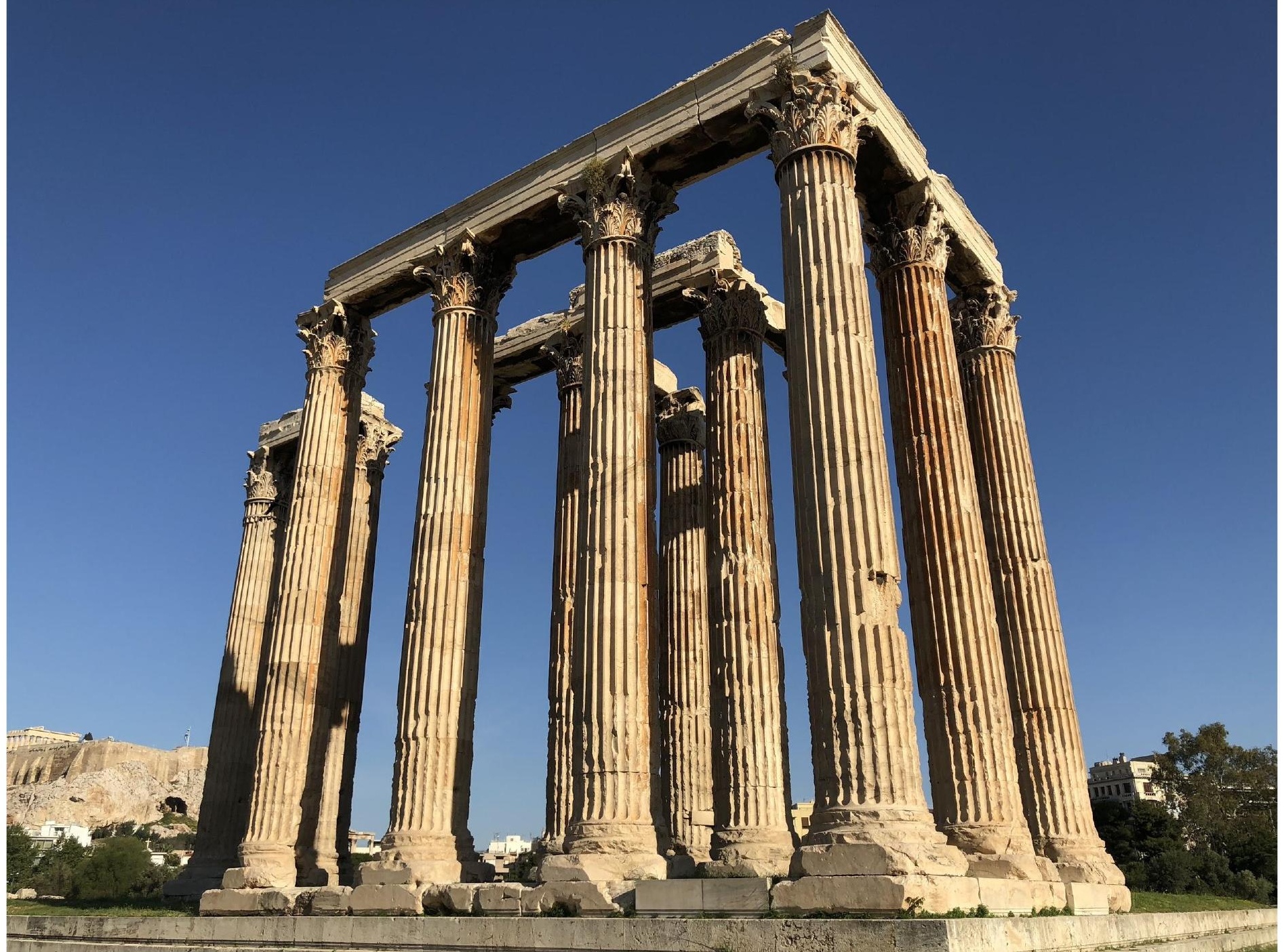


PHILOSOPHICAL

TRANSACTIONS:

\section{A C C O M P T}

OF THE PRESEN

Undertakings, Studies, and Labours

OF THE

I $N G \mathbb{E}$ I O U S I N M A N $Y$

CONSIDERABLE PARTS OF THE

W $O R \quad L \quad D$.

\section{Vol I.}

For Anno 1665 , and 1666 .

In the $S A V O Y$

Printed by T.N. for Fohn Martyn ar the Bell, a little with-

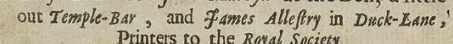

Irosented by the Author May. $30^{\text {th }} \mathrm{J} 66 \mathrm{Or}$.
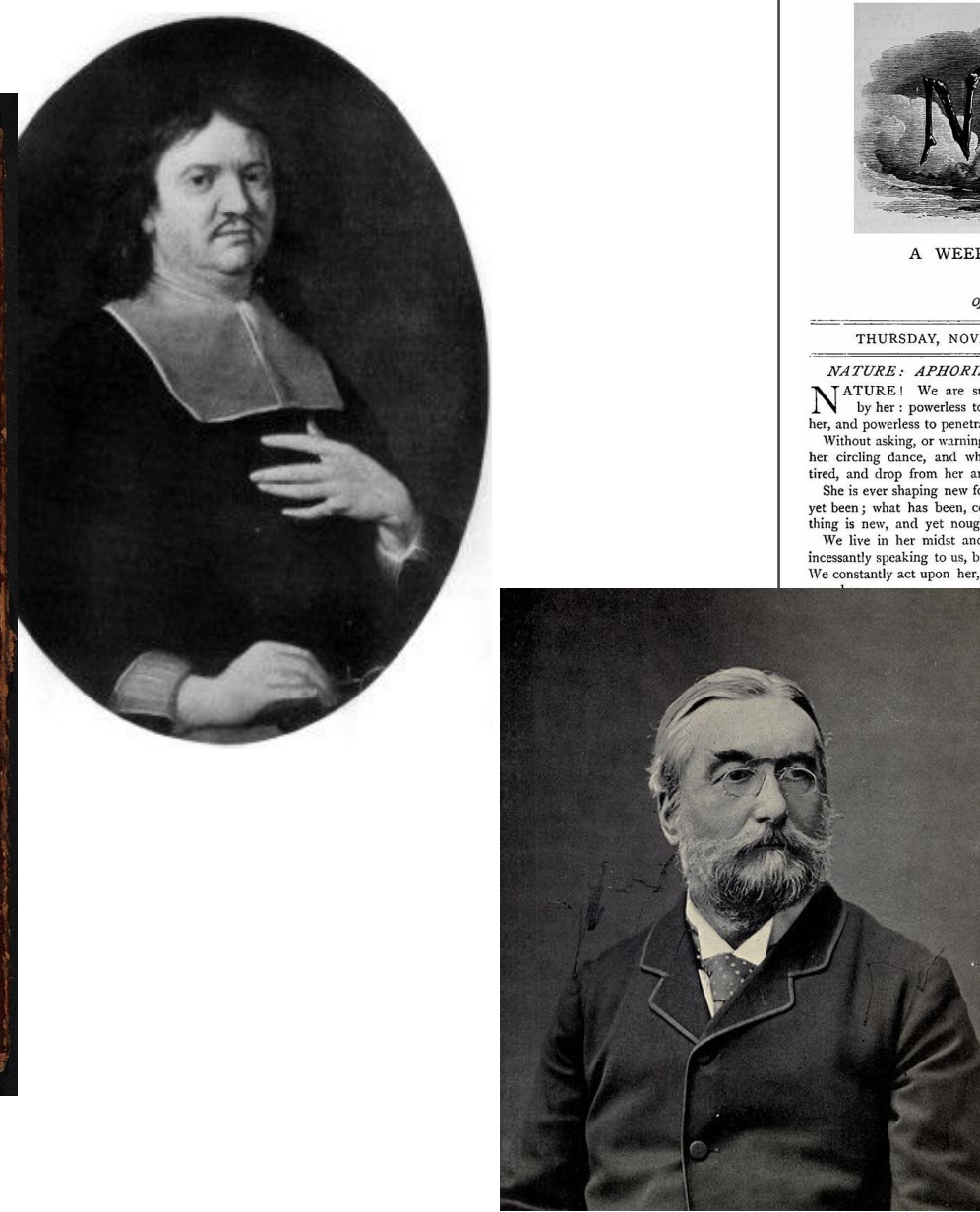

\section{TATURE}

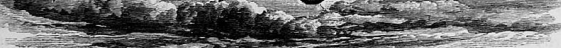

A WEEKLY ILLUSTRATED JOURNAL OF SCIENCE

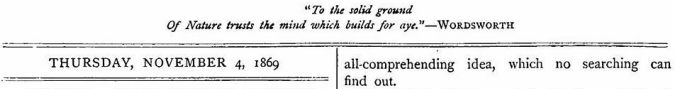

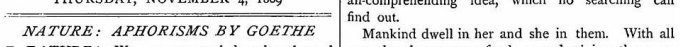
ATURE! We are surrounded and embraced
by her : powerless to separate ourselves from
men she plays a game for love, and rejocices the more
they win. With many, her moves are so hidden, that 列, or warning, she snatches her circling dance, and whirls us on until we are
tired end She is ever shaping new forms: what is, has never
yet been; what has been, comes not again. Every Whe loves herself and her ind

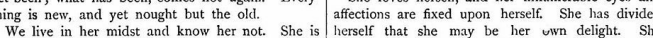
hicessantly speaking to us, but betrays not her secret. canses an endless succession of new capacities aim at is Individuality; $; \begin{gathered}\text { may be assuaged. } \\ \text { She recioces in illusion. Whoso destroys it in him- }\end{gathered}$ viduals. She is always
but her workshop is but where is the mother? Her children are numberless. To none is she ing-up the most uniform altogether miserly; but she has her favourites, on
yriviving without a trace
whom she squanders much, and for whom she makes

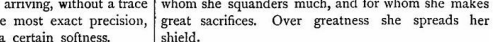

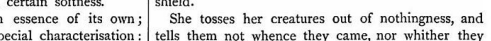
\begin{tabular}{l|l} 
nity. \\
now not whether she sees
\end{tabular}

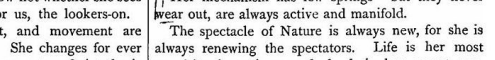
She changes for ever always renewing the spectators. Life is her most
and he has laid her curse trivance to get plenty of life

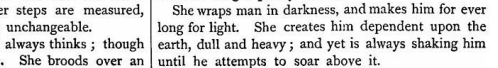




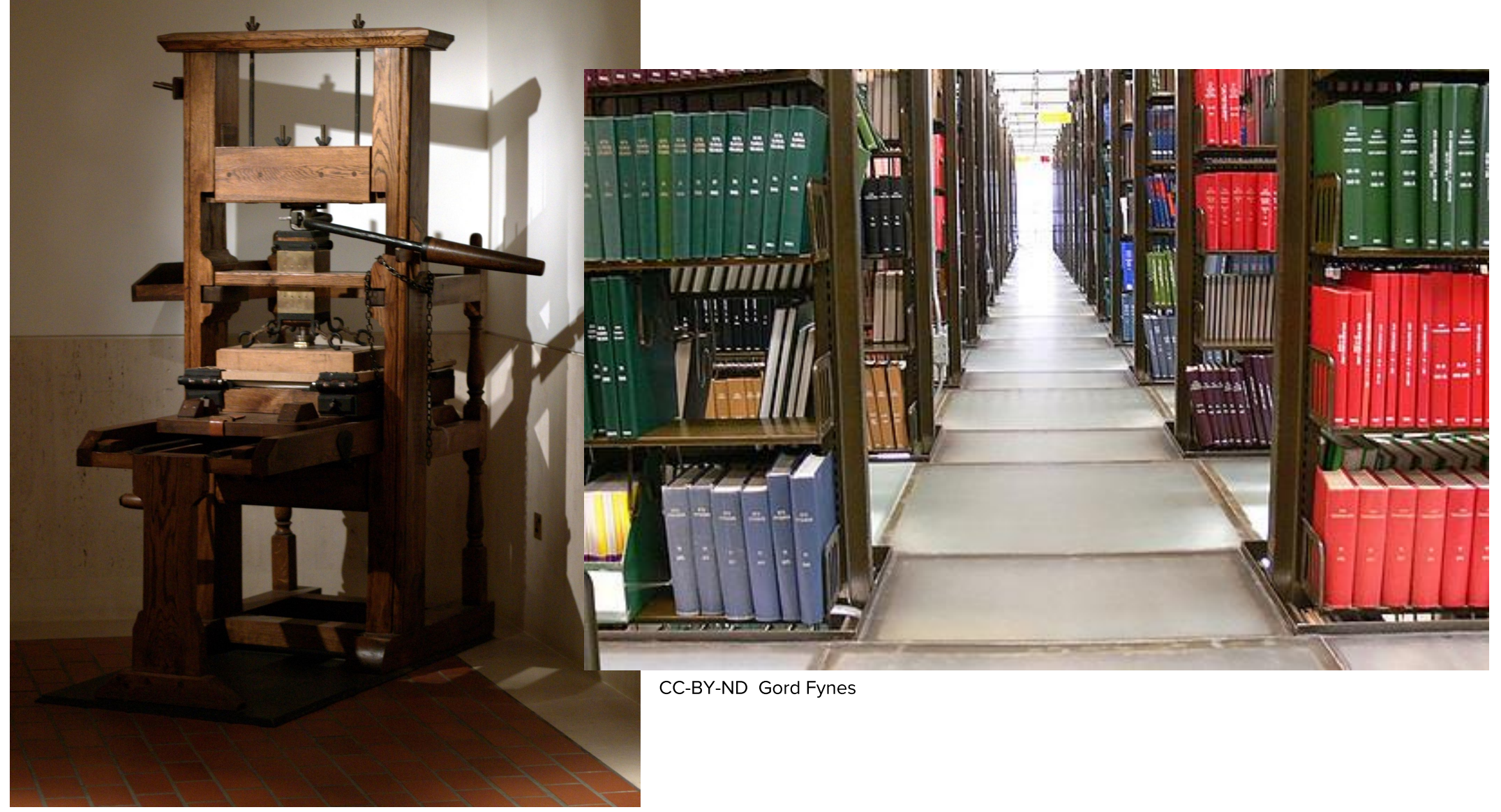



Author
Editor
Peers
Author
Journal
Writes
checks
review
revises
publishes

From a publishing tech perspective... 
Submission Production Delivery 


\section{Problems}

- Long revision cycles

- Few in-browser editing capabilities

Submission

- Communication often external to system

- Author uploads manuscript $\&$ adds metadata

- Editor checks manuscript

- \& assigns reviewers

- Reviewers provide feedback 


\section{Problems}

- Separate systems

- Typesetting often offshore

- Expensive \& time consuming

\section{Submission Production}

- Production tracking system to produce, convert, \& prepare content

- Typesetting vendors who prepare manuscript for print \& convert documents into XML \& PDF 


\section{Problems}

- Separate system

- Many different options means integration is difficult

- Expensive and time-consuming

- Convert to HTML

- Display on web

- Make available for printing

- Search, version maintenance

- Syndication to PubMed, Scopus, Google, ... 


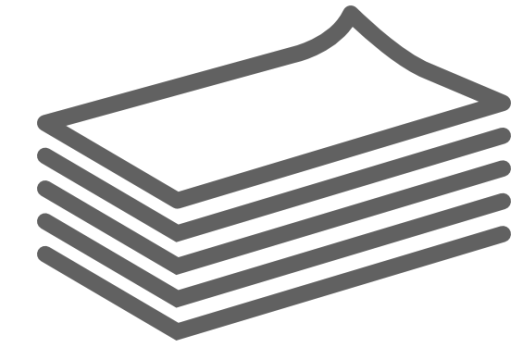

Submission

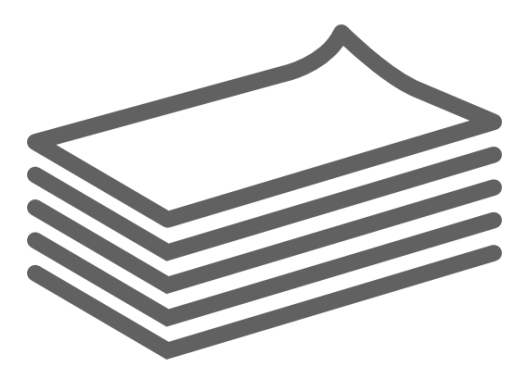

Production

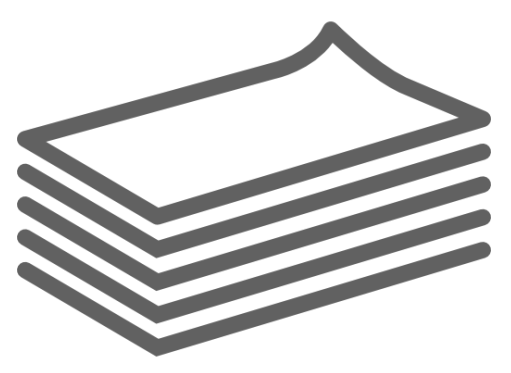

Delivery

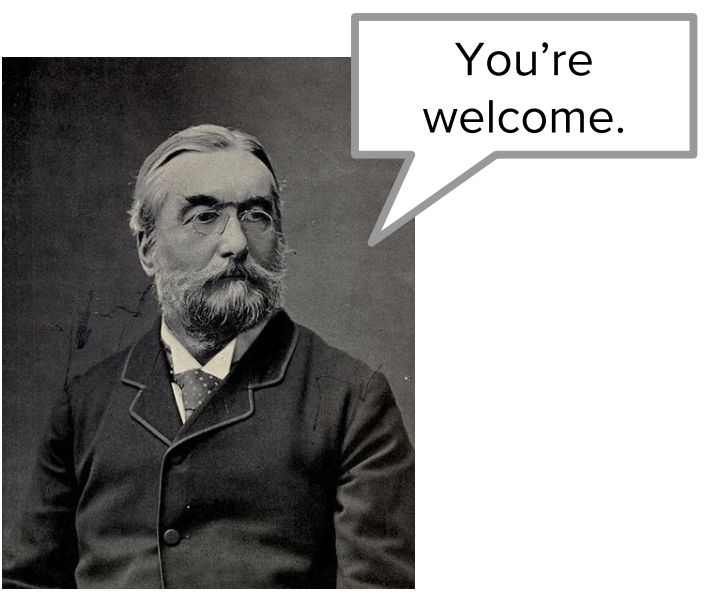




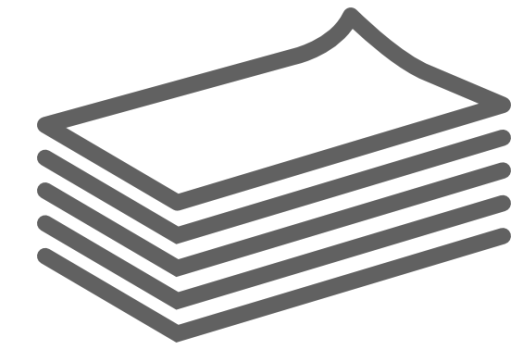

Submission

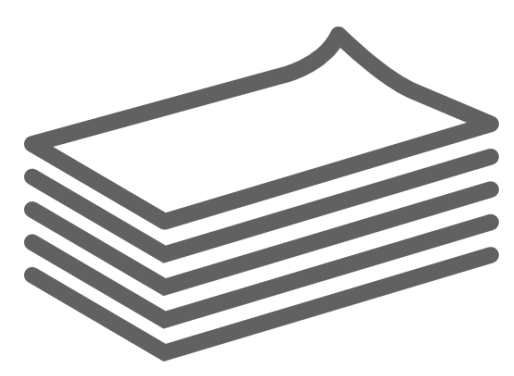

Production

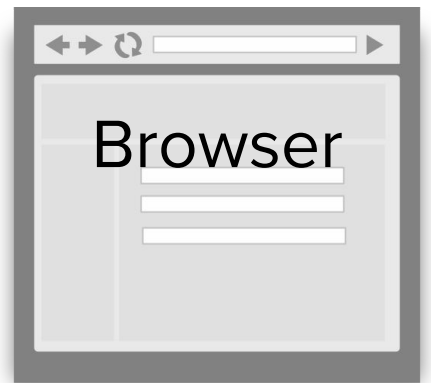

Delivery 
Submission

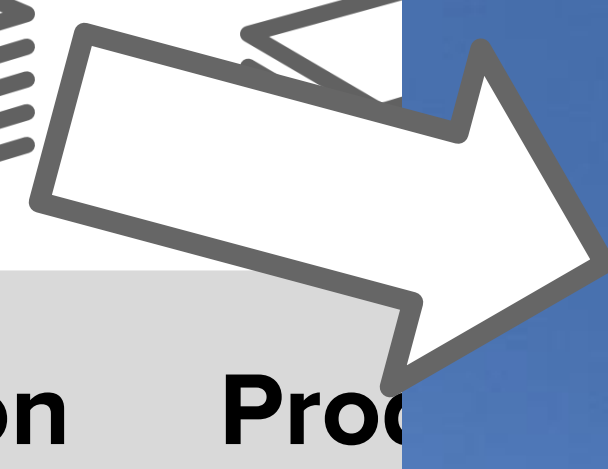




\section{Submission Production Delivery}

The effects of print persist... 


\section{Delivery}
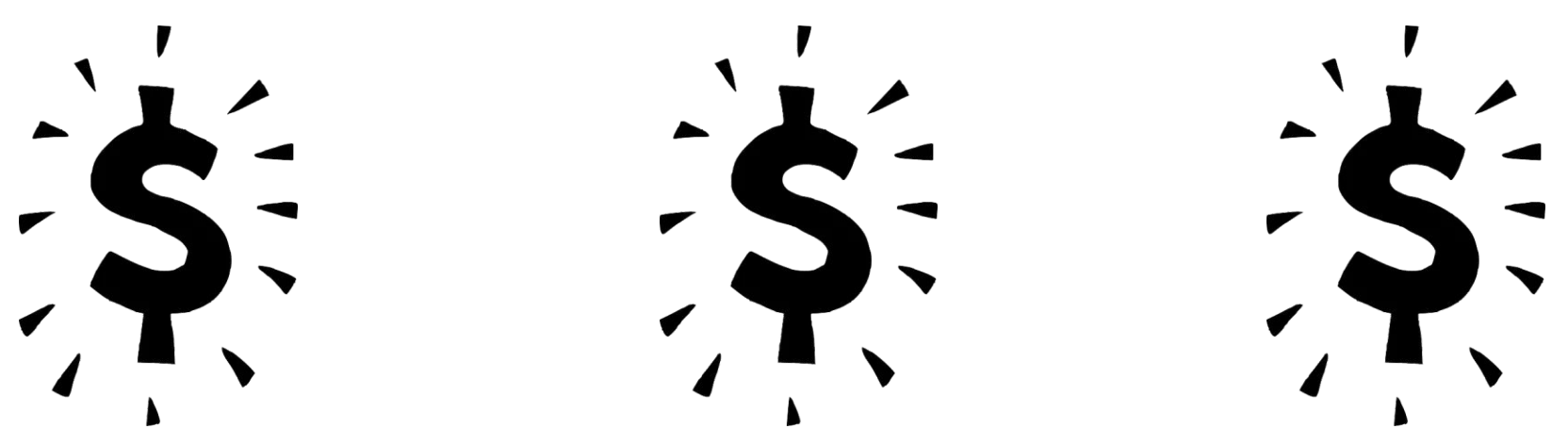


\section{Submission}

\section{Production}

Delivery
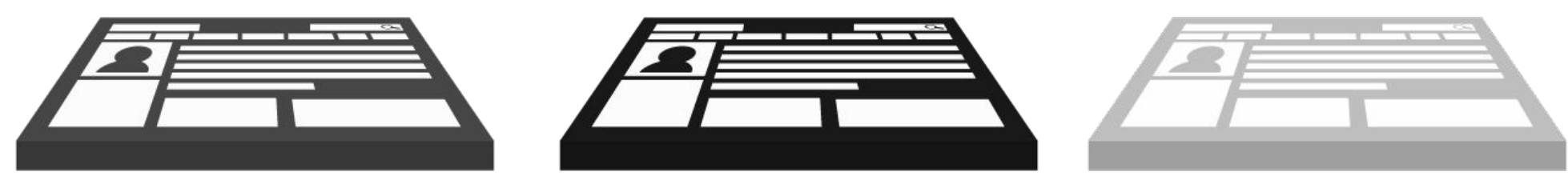
Submission

\section{Production}

\section{Delivery}
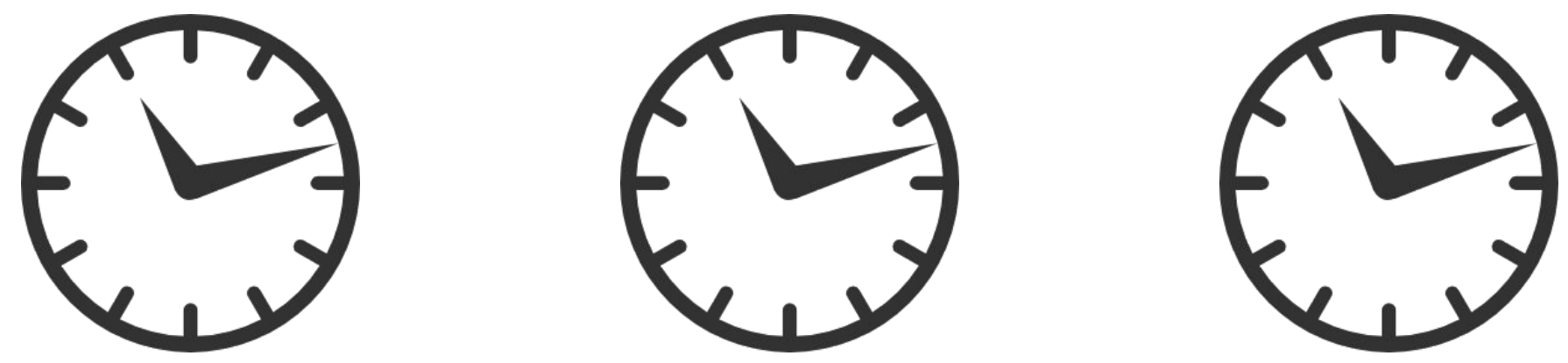

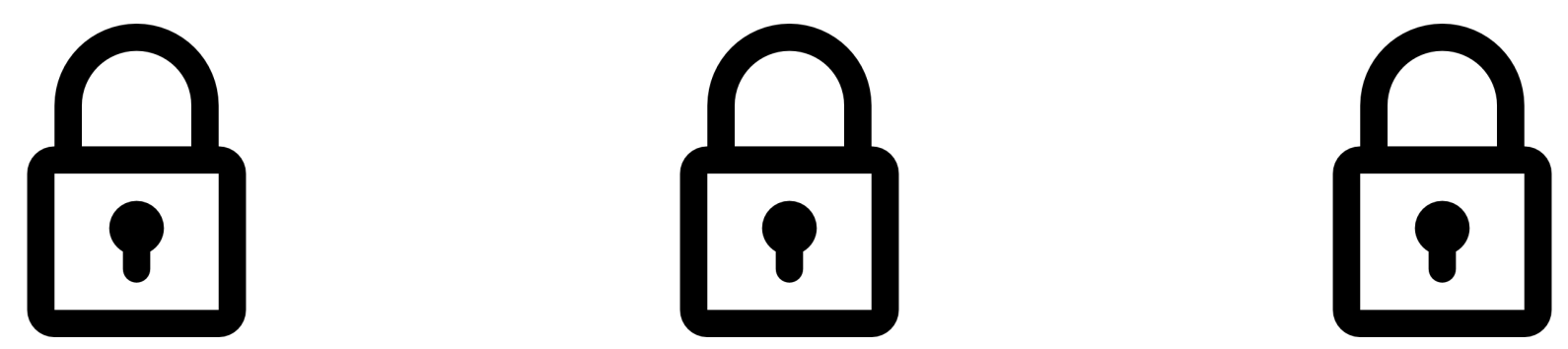


\section{Submission}

\section{Production}

\section{Delivery}
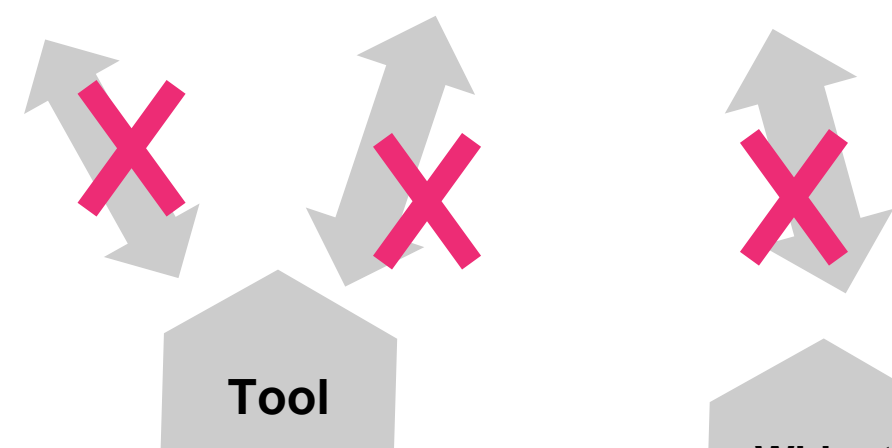
Where the communication goes 


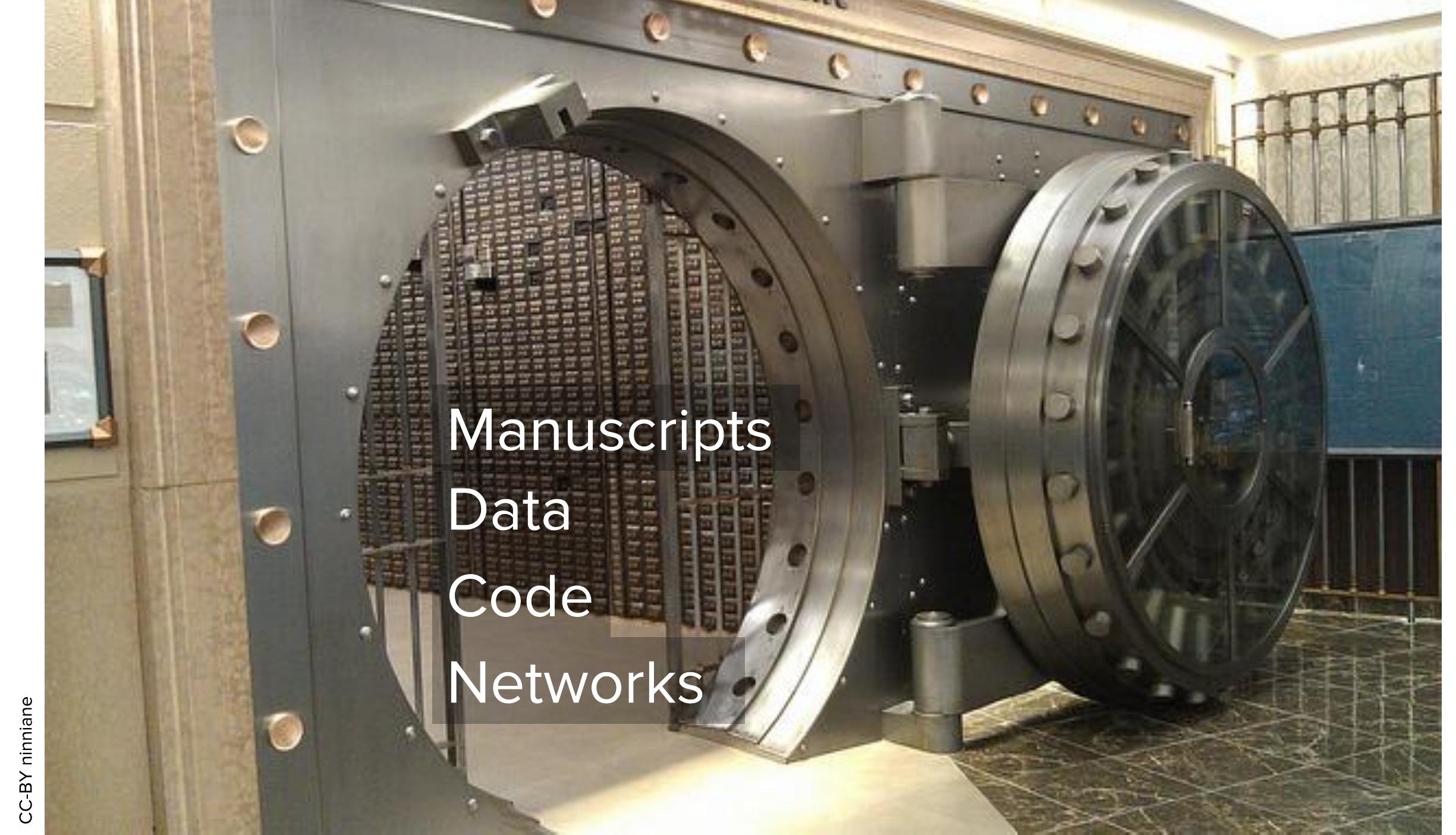


Where the communication isn't going 


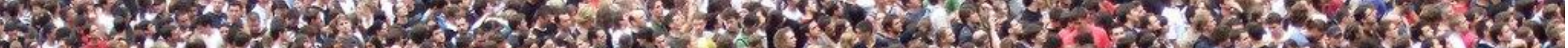

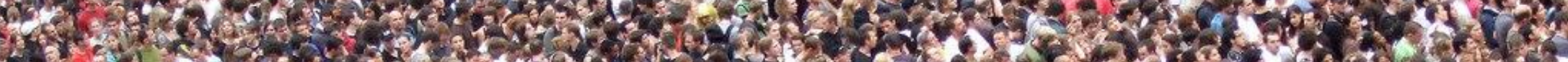

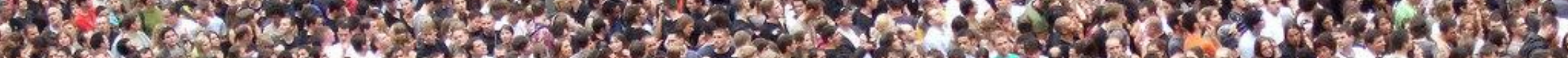

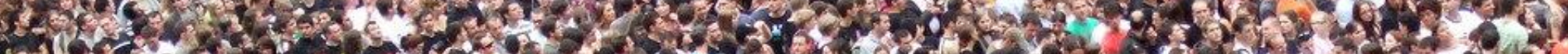

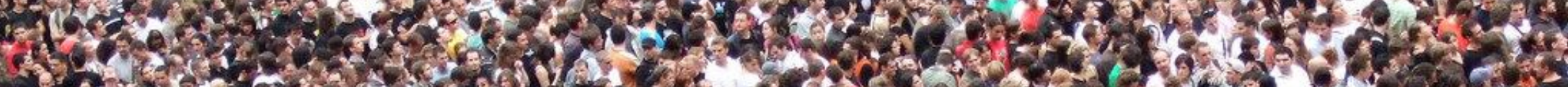

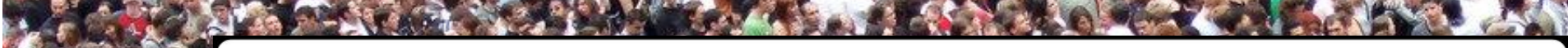
- $x^{2}=2$ - 125 a Ans Sur a - $x^{2} y^{2}$ - 5$]^{2}$ (1) bes 48

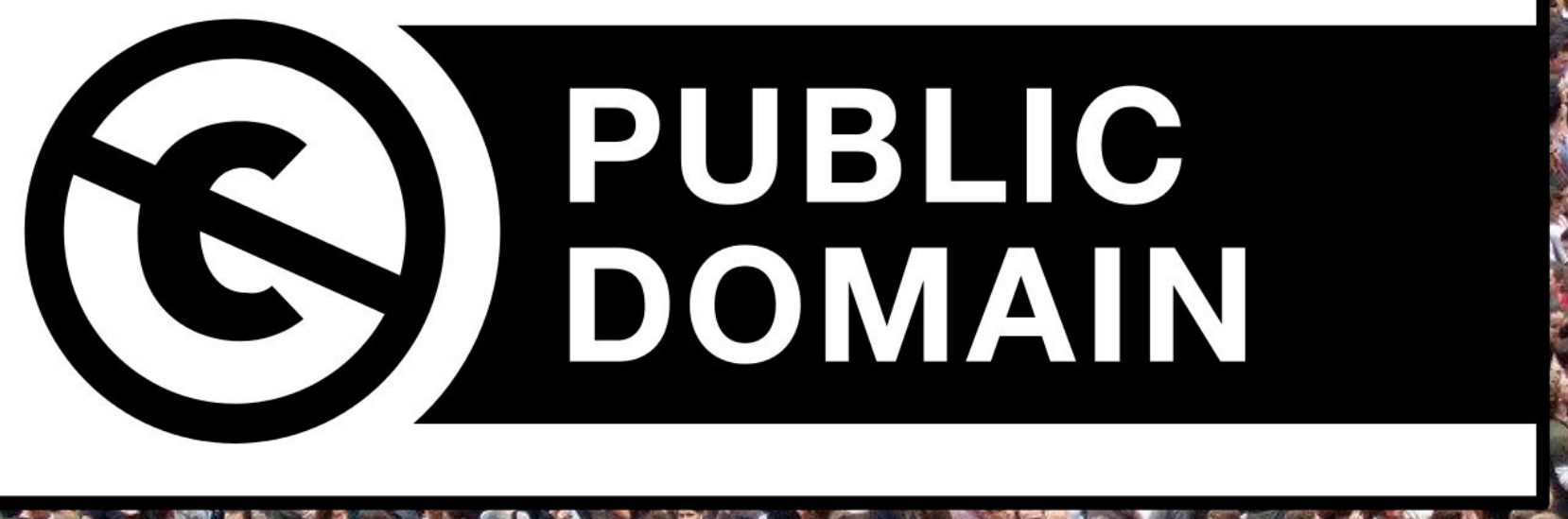
$-25 x$ $c^{2}+3 x$ 2.2. 12 (3) 3 a - $12=4$ S. 1,1 (t) 12 $3(2)=2$ - 2.20

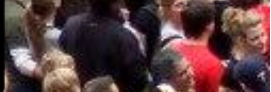

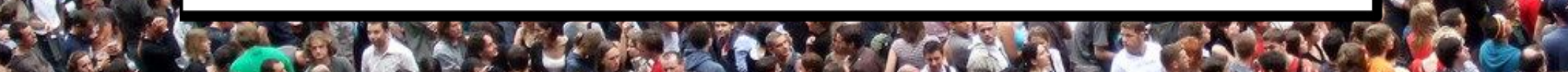

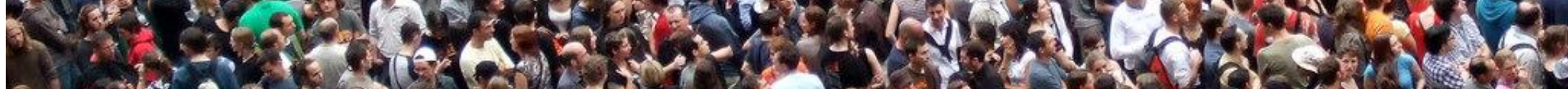

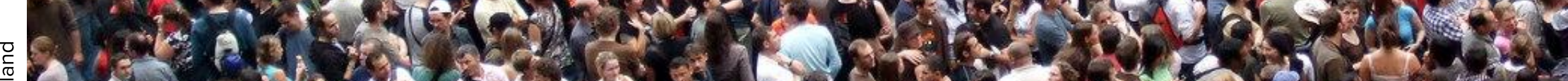

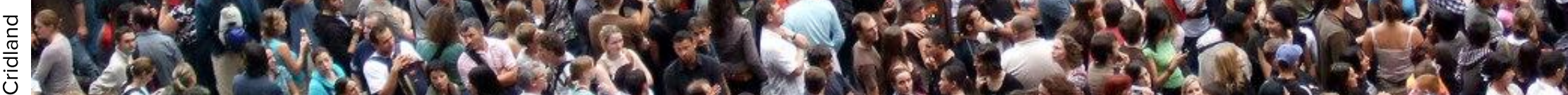

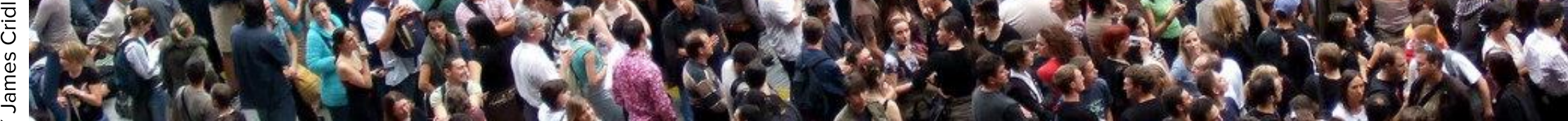

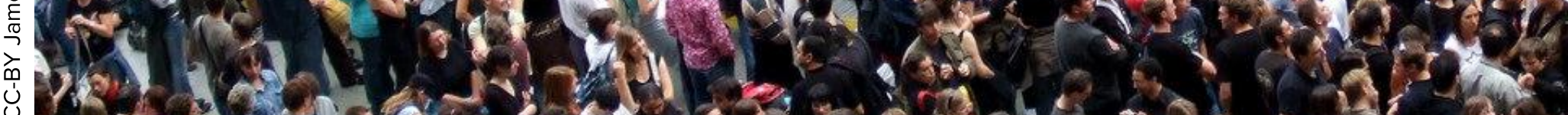

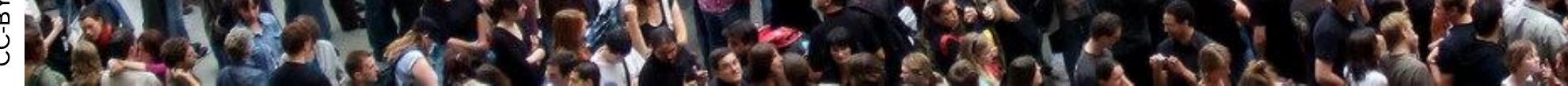


Who receives the communication 


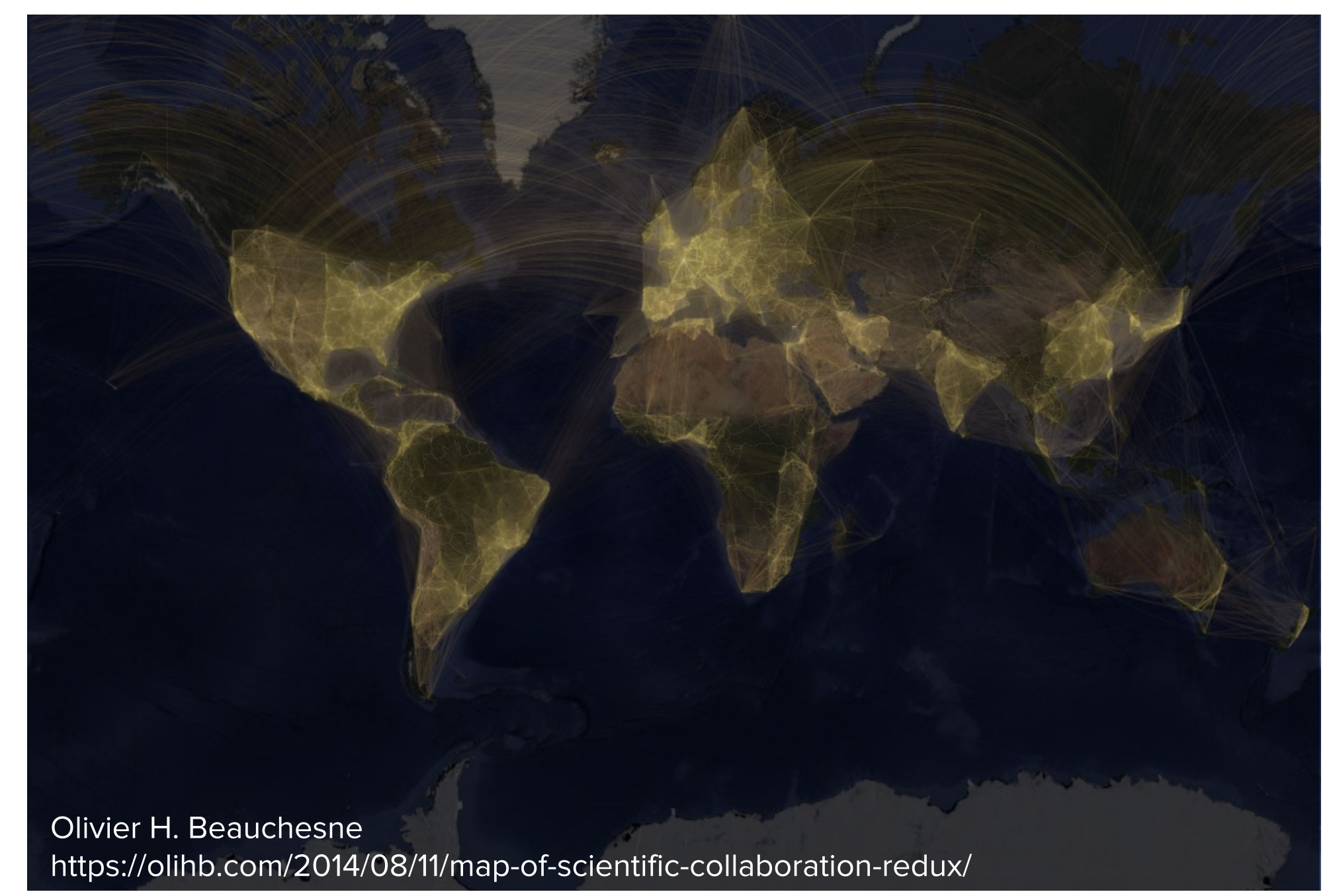




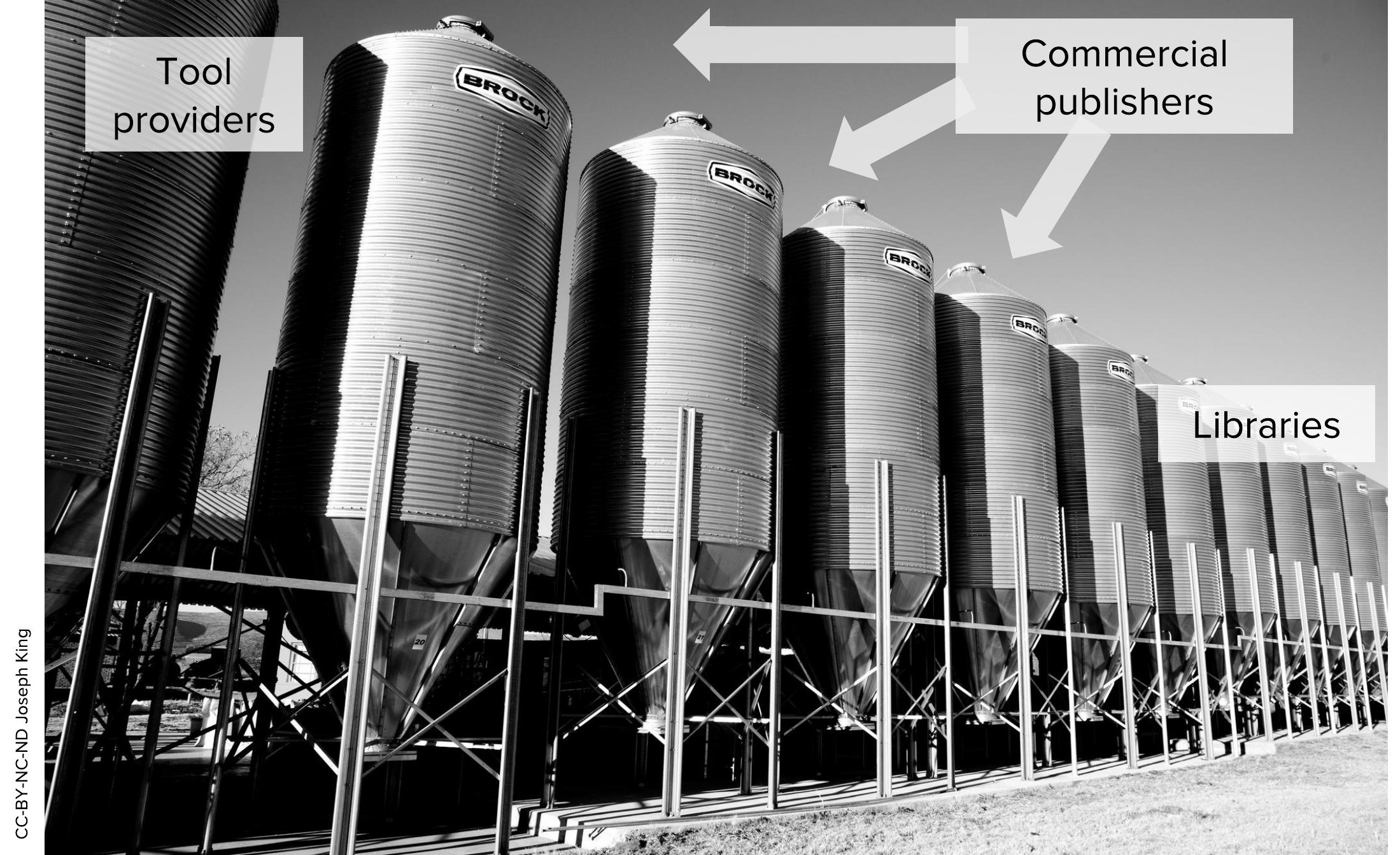


A vision for scholarly communication

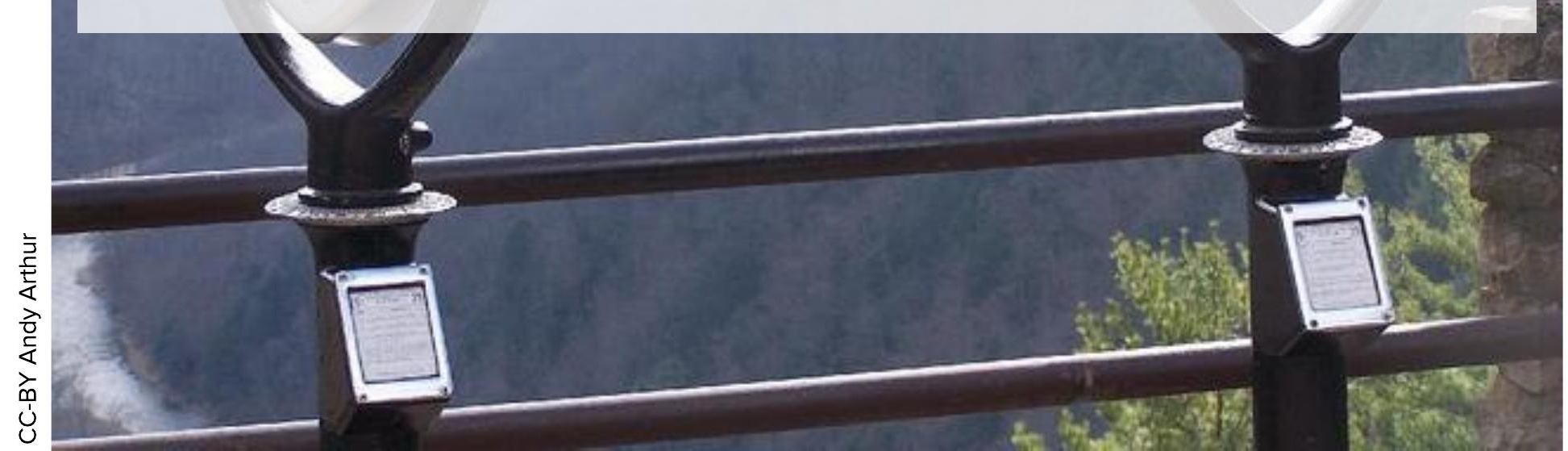




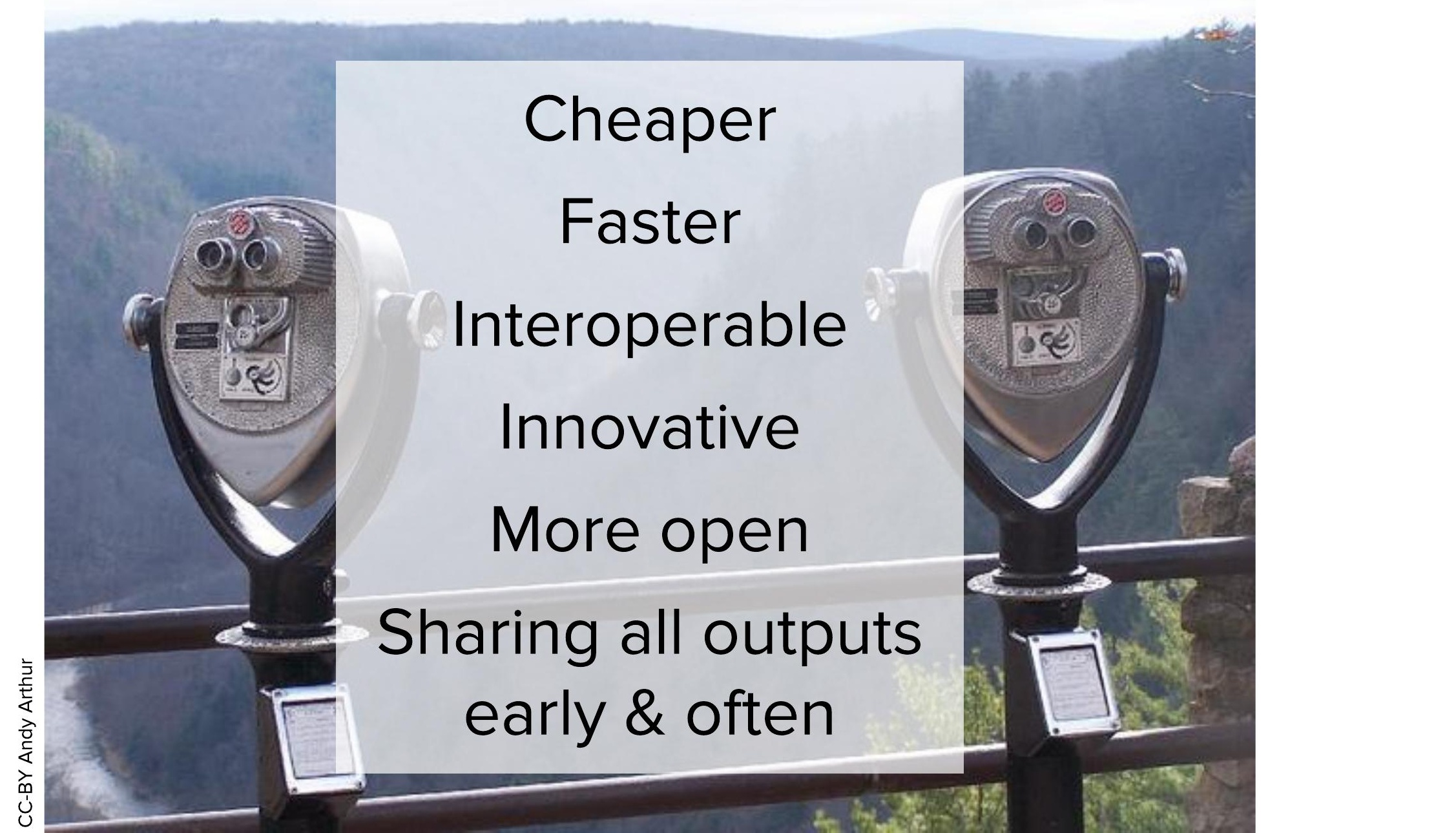




\section{Better scholarly communication research}

$\checkmark$ Reproducible

$\checkmark$ Transparent

$\checkmark$ Open

$\checkmark$ Available

$\checkmark$ Faster \& earlier 


\section{Connected \\ outputs}

Jennifer Lin: http://blog.crossref.org/ 2016/08/the-article-nexus.html

Data \& software

$\langle/\rangle$

Preprints

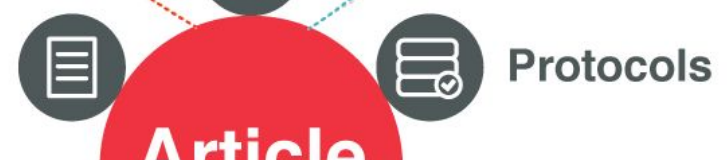

Article

Videos

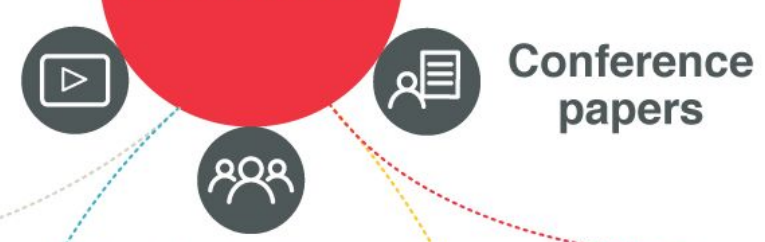

Published peer reviews 


\section{Living documents}

Notebook

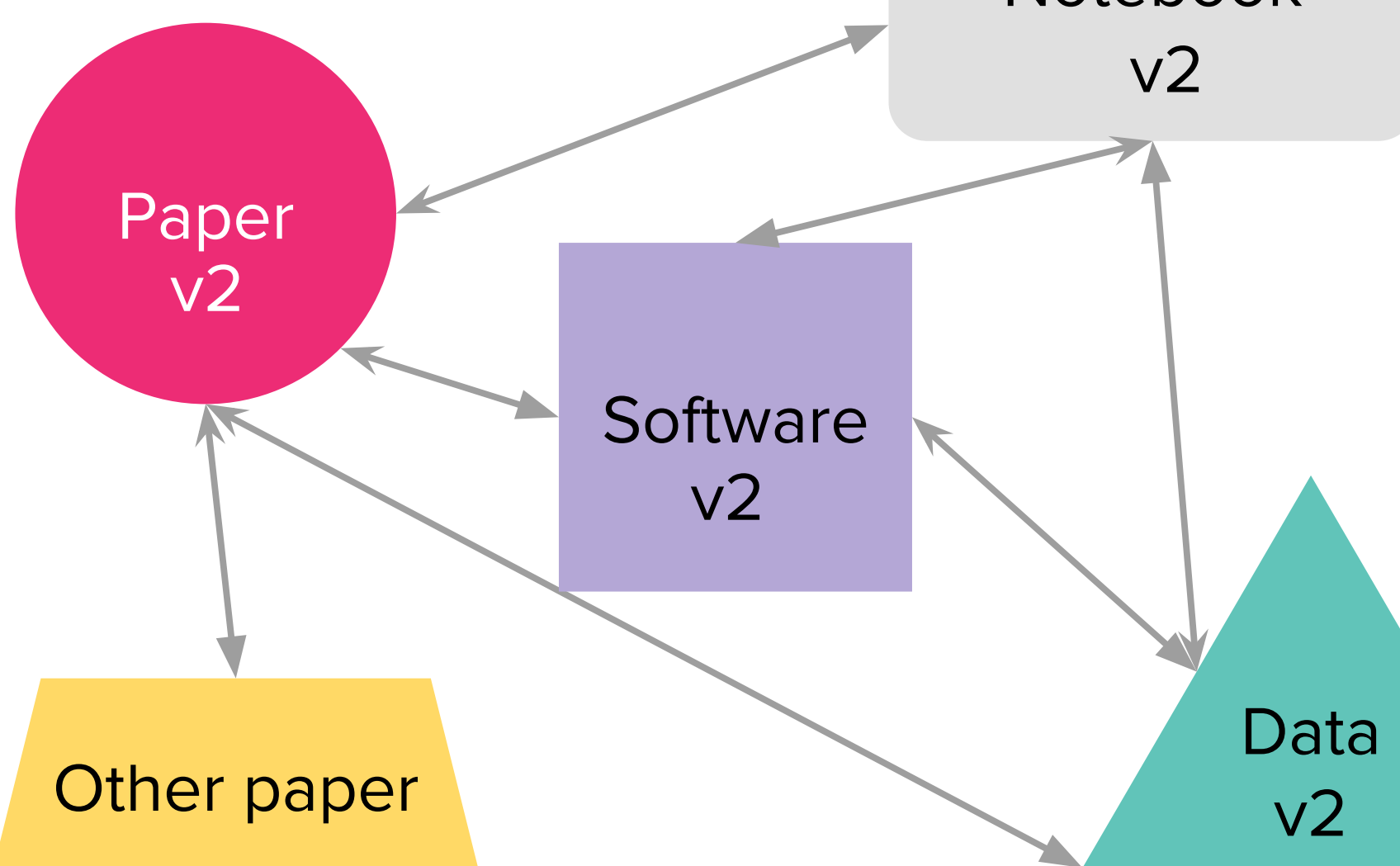




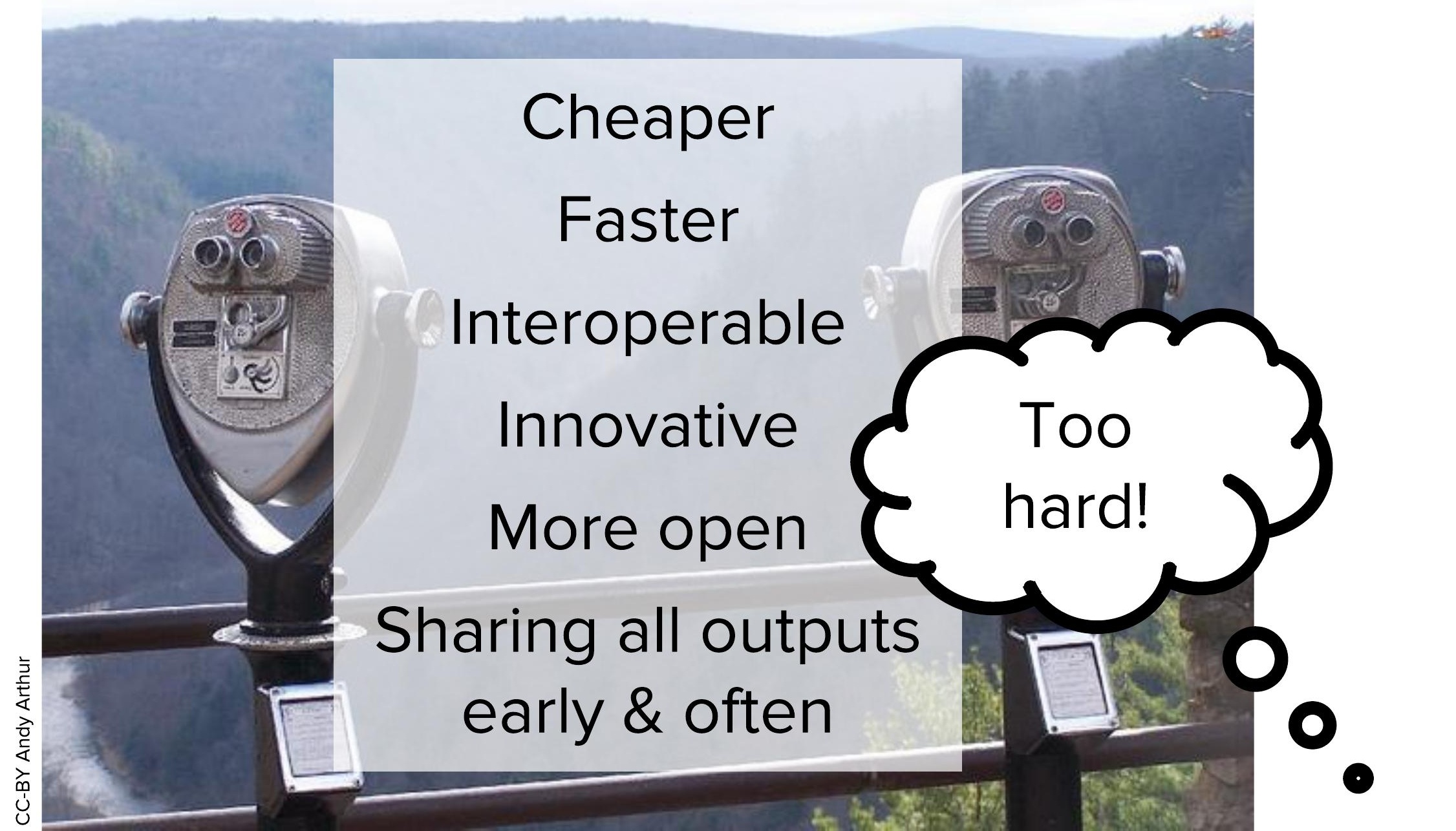


ARPA. NETWORK, LOGICAL MAP, MAY 1973

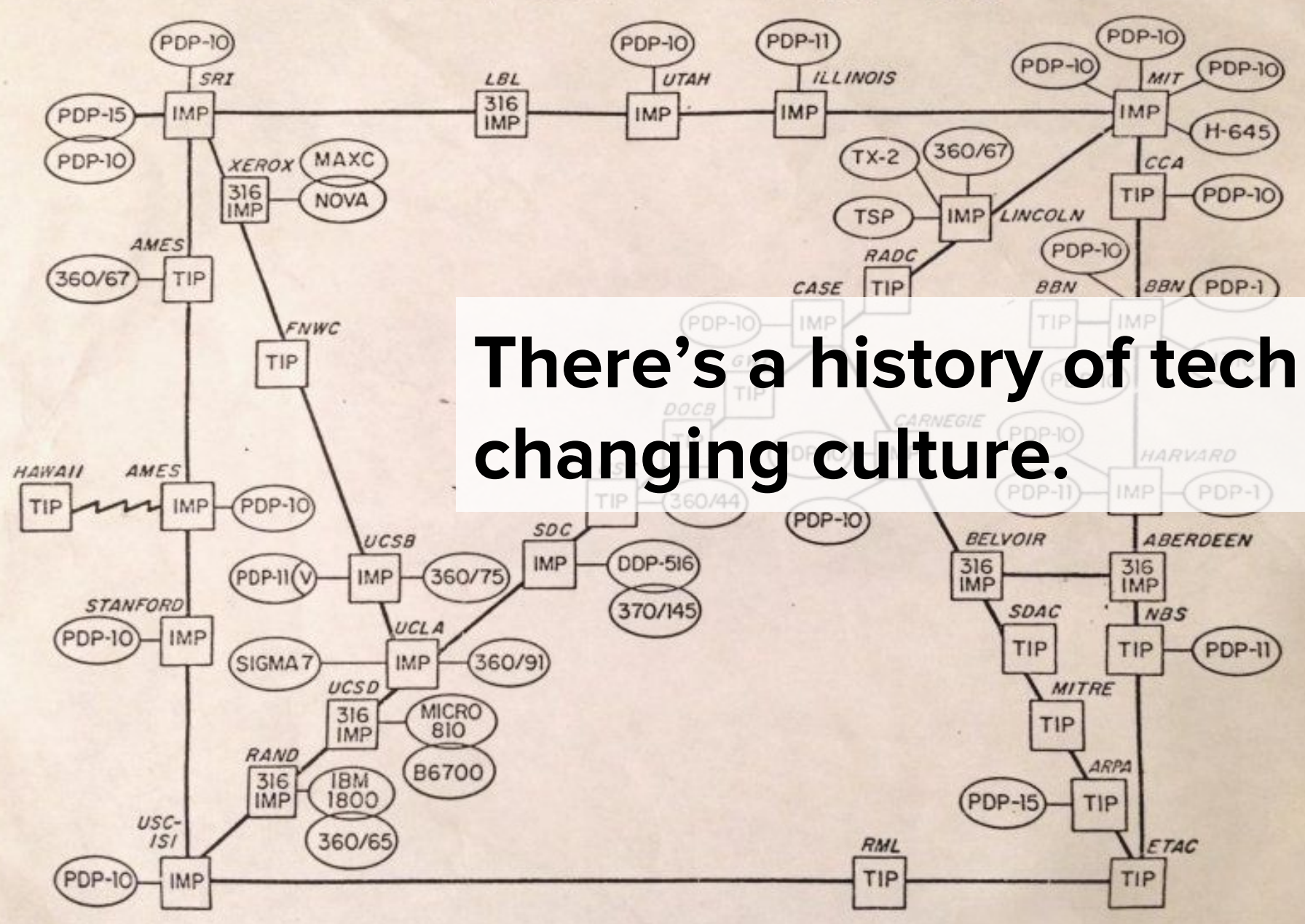




\section{A shared vision...}

\section{() FORCE11
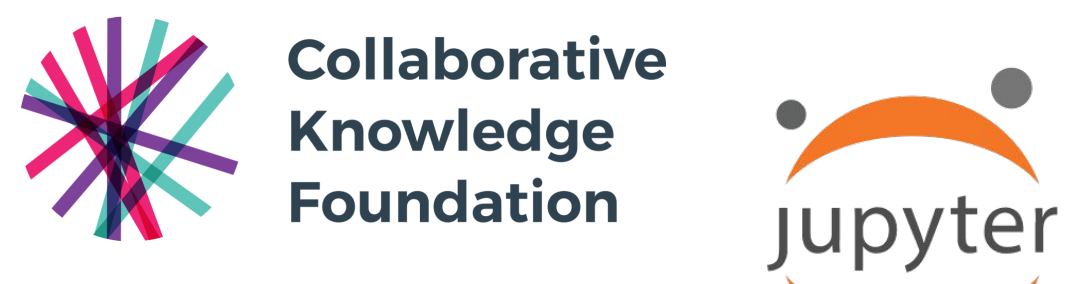

$\therefore$ PLOS PIII elIFE

Eiil Stencila 


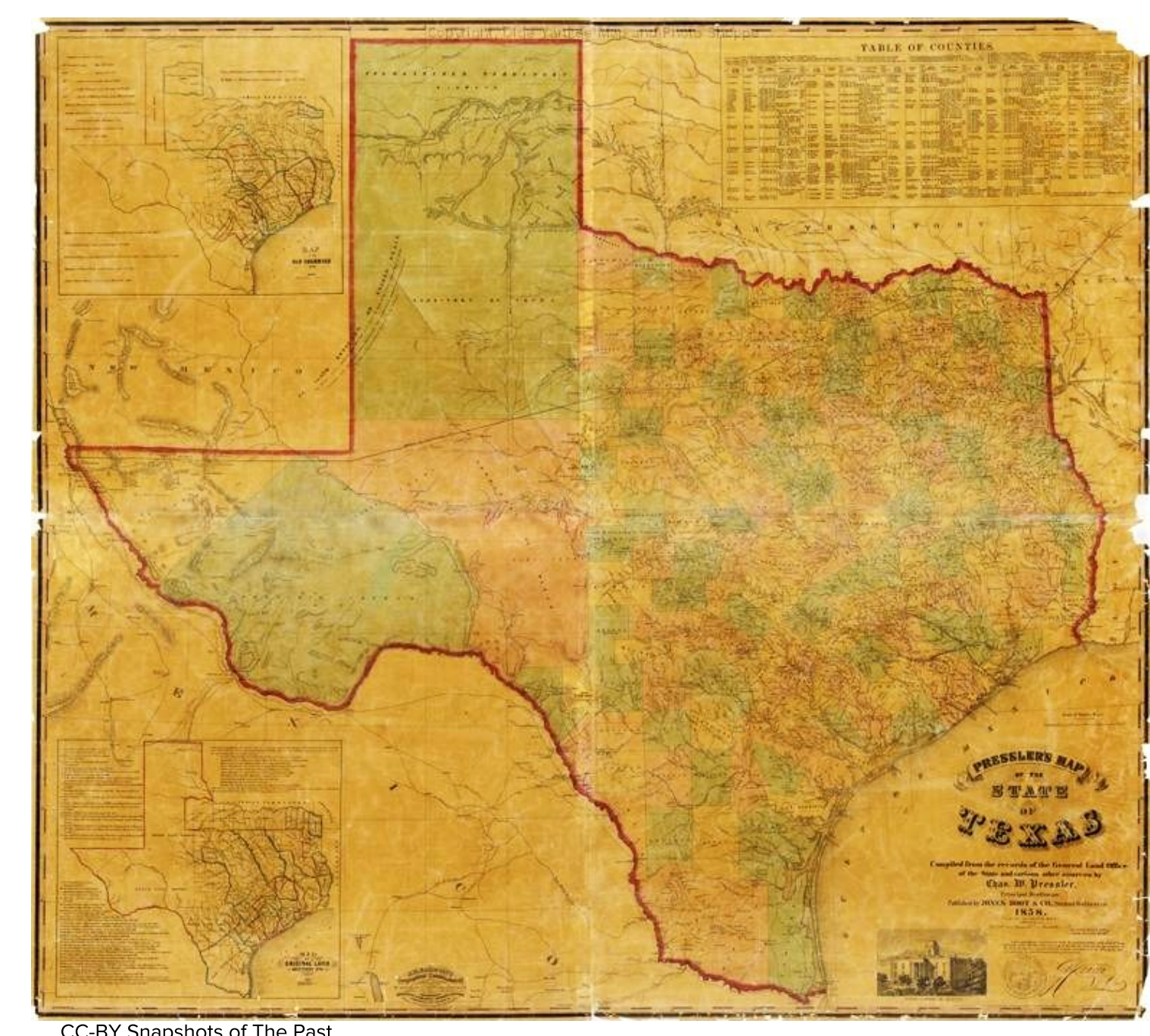

\section{How do we get there?}


open source modular

for flexibility

together 


\section{Open Source Software}

Source code available

Licensed so that others can study, change and distribute to anyone and for anything

Developed in a public, collaborative manner

\section{OSS $\neq$ Free}


Firefox

Linux

GitLab

OSS $\neq$ Free

\section{Google}

Facebook

GitHub

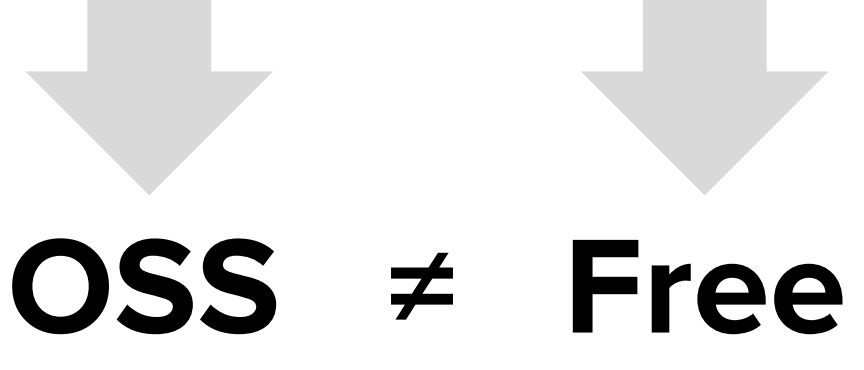




\section{Most publishing technology}

is neither

OSS nor Free 
Expensive

Very slow

Static outputs

Duplicate databases

No interoperability

Less innovation

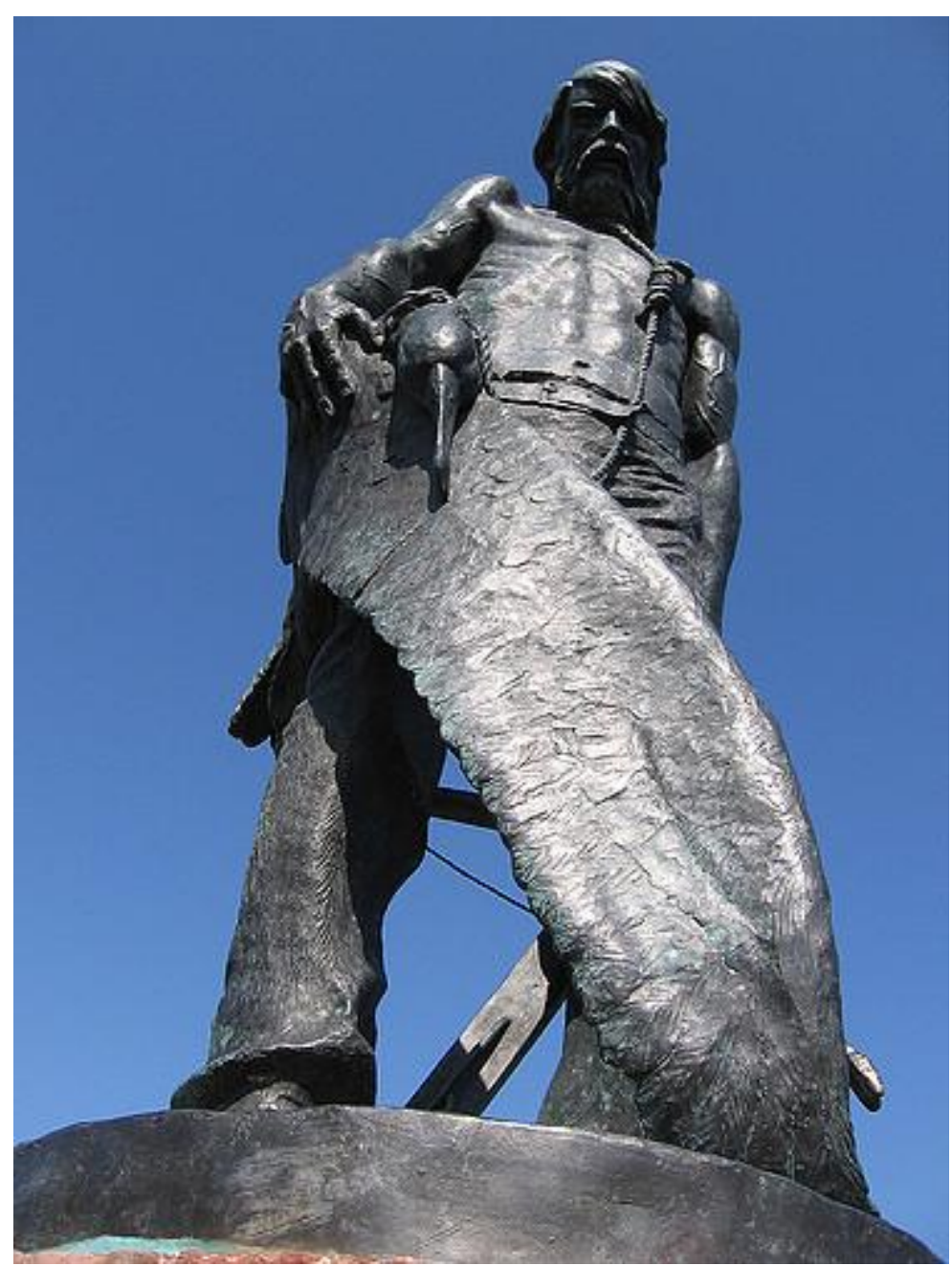




\section{Open Source Software}

Can be...

Reliable | Affordable | Profitable | Reusable 


\section{Open Source Software Successful Examples}

Internet

TCP/IP (governing protocols)

$75 \%$ adoption of OS browsers (Chrome, Firefox)

$50 \%$ of websites delivered by Apache web server

$70 \%$ of sites use WordPress, Joomla or Drupal as a CMS

\section{Phones}

Android, iOS (built on OS Darwin operating system) dominates

\section{Cloud hosting services}

OpenStack has 17\% market share against Amazon, Microsoft and Google 


\title{
Open Source Software
}

\section{Can be...}

\section{Reliable | Affordable | Profitable | Reusable}

\author{
Is best when it's...
}

Collaborative I Community-driven 


\section{Commercial publishers \\ University presses}

Funders

Libraries

Tool providers

Authors

Collaborative I Community-driven 


\section{Collaborative Knowledge Foundation}

Coko: we build open source solutions to transform research communication 


\section{Collaborative Knowledge Foundation}

No one platform can solve all the problems.

We need an ecosystem of tools and software.

We should build modular \& interoperable things.

The community must create and own solutions. 


\section{PubSweet}

Coko's component-based framework for building publishing platforms

Open source | Modular | Flexible

Built with the community 


\section{PubSweet}

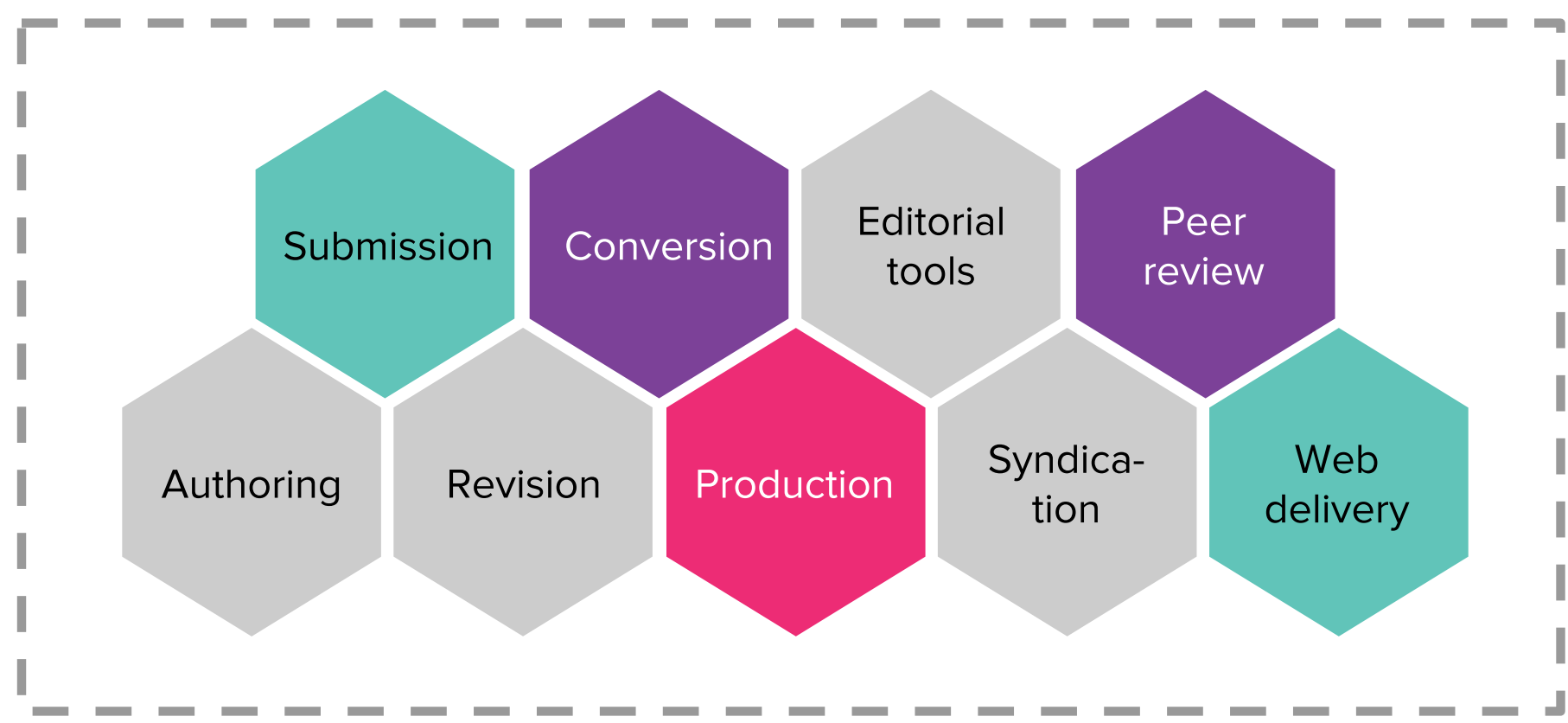




\section{\# PubSweet \\ Open, modular architecture}

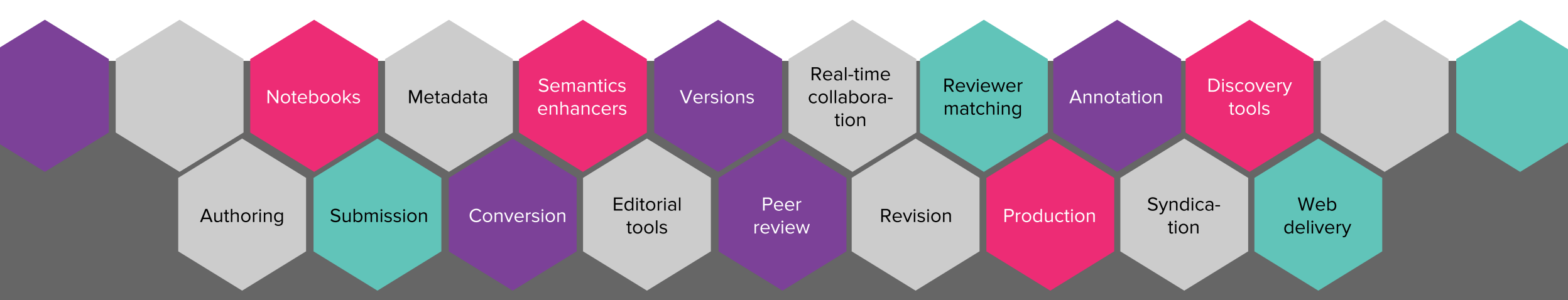

\section{PubSweet Publishing Framework}




\section{Micropublications: brief communications}

WermBase
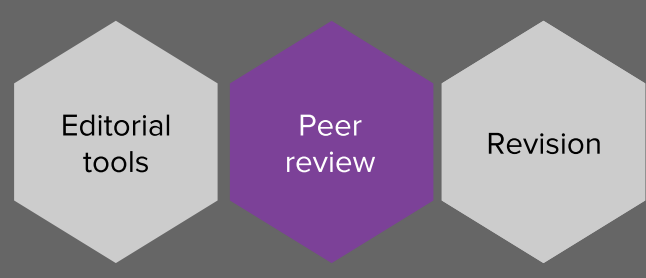

Production 


\section{A new mutation with a polycystin phenotypic spectrum in Caenorhabditis elegans}

Allyson Whittaker1, Gary Schindelman1, Shahla Gharib1, and Paul W. Sternberg1

1. Division of Biology and Biological Engineering, Caltech, Pasadena CA 91125

\section{Description:}

lov-1 and pkd-2, which encode the $C$. elegans orthologs of human polycystin-1 and -2 , are necessary for three particular aspects of male mating behavior. In a screen for male mating defective mutants with similar spectrum of mating defects, we identified a mutation that apparently defines a new locus, lov-3.

We isolated the sy682 mutation in an ethyl-methane sulphonate (EMS)-screen of Caenorhabditis elegans strain PS1395 Igenotype: plg-1(e2001d): him-5(e1490)l for mutant males that do not mate efficiently and hence do not form plugs on hermaphrodites (Liu et al, 2017). sy682 is defective in the males' response to contact with hermaphrodite and in vulval location (Table 1). The vulval location defect is failing to stop at the vulva. These two phenotypes are associated with lov-1 (Barr, 1999) and pkd-2 loss-of-function mutations (Barr et al. 2001 Whittaker et al., 2017). sy682 maps to the X chromosome and thus is distinct from lov-1 and pkd-2, so it defines a likely new locus, lov-3

\begin{tabular}{|l|l|l|}
\hline Genotype & Phenotype \\
\hline & response & vulval location \\
\hline$+/+$ & $47 / 59$ & $57 / 57$ \\
\hline sy682/sy682 & $12 / 61$ & $25 / 44$ \\
\hline
\end{tabular}

Table 1. Phenotypic analysis of sy682 mutation. Response, response to contact with hermaphrodite proportion of males that responded to initial contact with a hermaphrodite. Vulval location, the proportion of males that located the vulva on the first attempt. See Barr \& Sternberg (1999) for details.

\section{Reagents}

\section{Strains:}

PS4770: plg-1(e2001d)); him-5(e1490); sy682

PS6219: plg-1(e2001): him-5(e1490); sy682. sy682 backcrossed 1x

PS1395: plg-1(e2001d): him-5(e1490)

\section{References}

Barr MM, Sternberg PW. A polycystic kidney-disease gene homologue required for male mating behaviour in C. elegans. Nature. 1999 Sep 23:401(6751):386-9 PubMed PMID: 10517638

Barr MM, DeModena J, Braun D, Nguyen CQ, Hall DH, Sternberg PW. The Caenorhabditis elegans autosomal dominant polycystic kidney disease gene homologs lov-1 and pkd-2 act in the same pathway. Curr Biol. 2001 Sep 4:11(17):1341-6. PubMed PMID: 11553327.

Liu, K; Hajdu-Cronin, Y; Chen, A; Schindelman, G; Whittaker, A; Gharib, S Sternberg. PW. (2017): Screening for C. elegans male copulation-defective mutants by the mating plug phenotype. Micropublication: biology Dataset. https://doi.org/10.17912/W/2SSgK

Whittaker, A; Schindelman, G; Gharib, S; Sternberg, PW. (2017): sy680 is a novel allele of $p k d-2$. Micropublication: biology Dataset. https://doi.org/10.17912/W/2SW/MM

\section{Funding:}

Howard Hughes Medical Institute, with whom PWS was an Investigator. 


\section{Editoria: book publishing}

甲

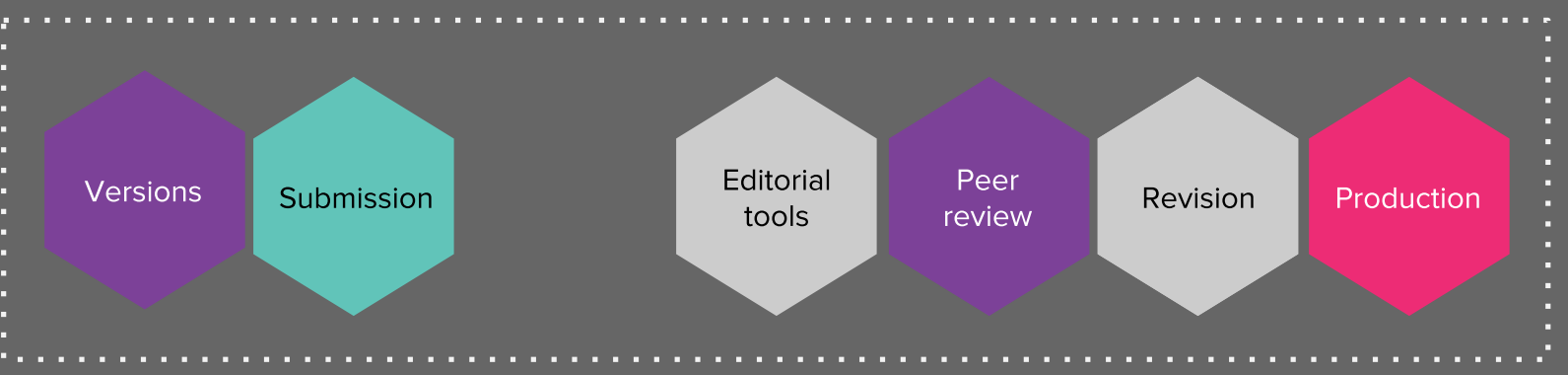

PubSweet Publishing Framework 
Production Editor: unassigned $\because 2$ TEAM MANAGER

\section{Migrating in to Financial Markets}

- 1 UPLOAd MULTIPLE WORd FILES D EXPORT BOOK

FRONTMATTER

$\bigoplus$ ADD COMPONENT

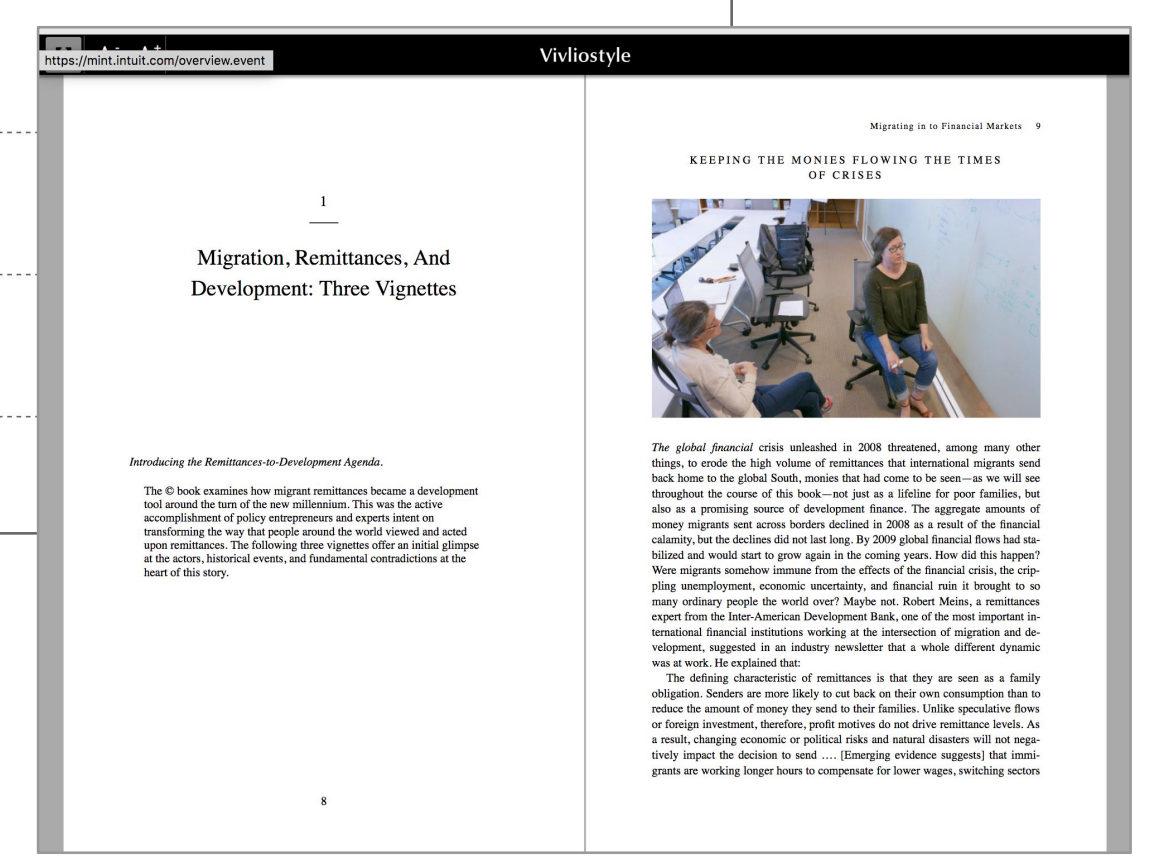

https://editoria.pub

aI_Bakker_title

e UPLOAD WORD To Clean $>$ To Edit $>$ To Review $>$ To Style

(a2_Bakker_toc

(1) UPLOAD WORD To Clean > To Edit > To Review > To Style

(a3_Bakker_ack

(1) UPLOAD WORD To Clean > To Edit > To Review > To Style

- editoria 


\section{xPub: a collection of PubSweet components}

for manuscript submission, review, \& revision
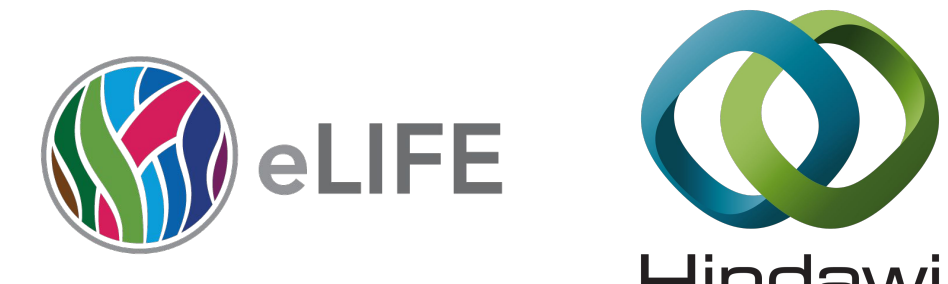

Hindawi

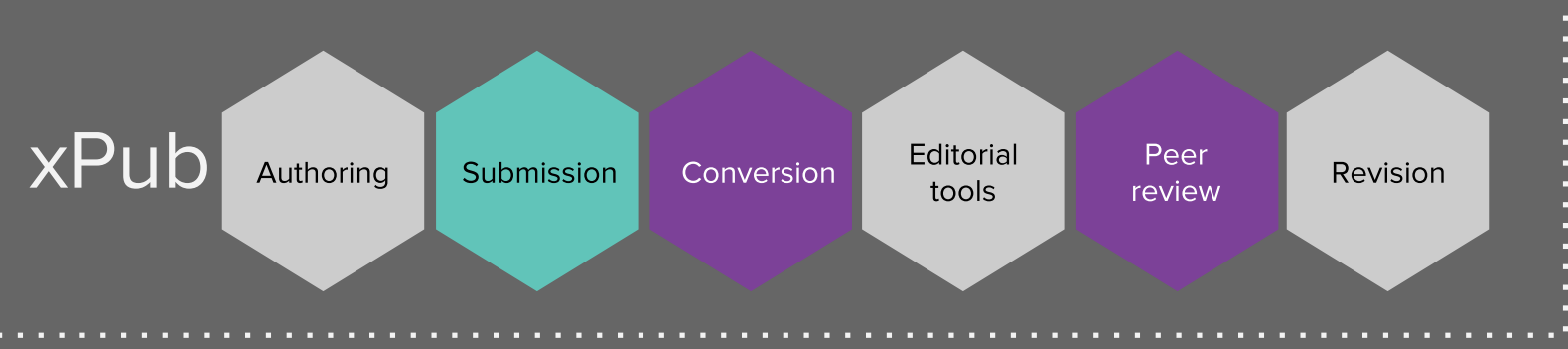

PubSweet Publishing Framework 


\section{The blame game: An investigation of} grammatical aspect and blame judgments

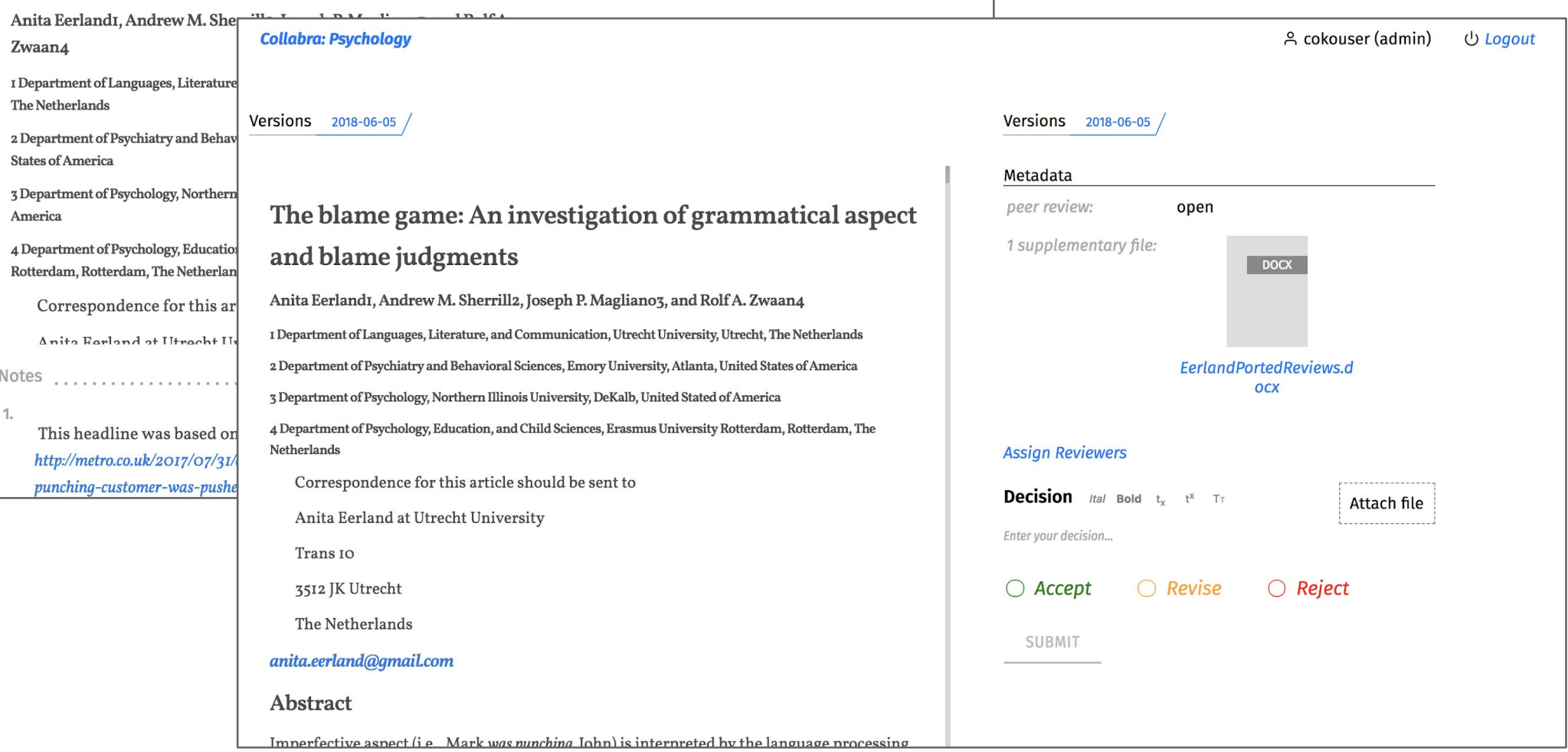


open source modular

for flexibility together

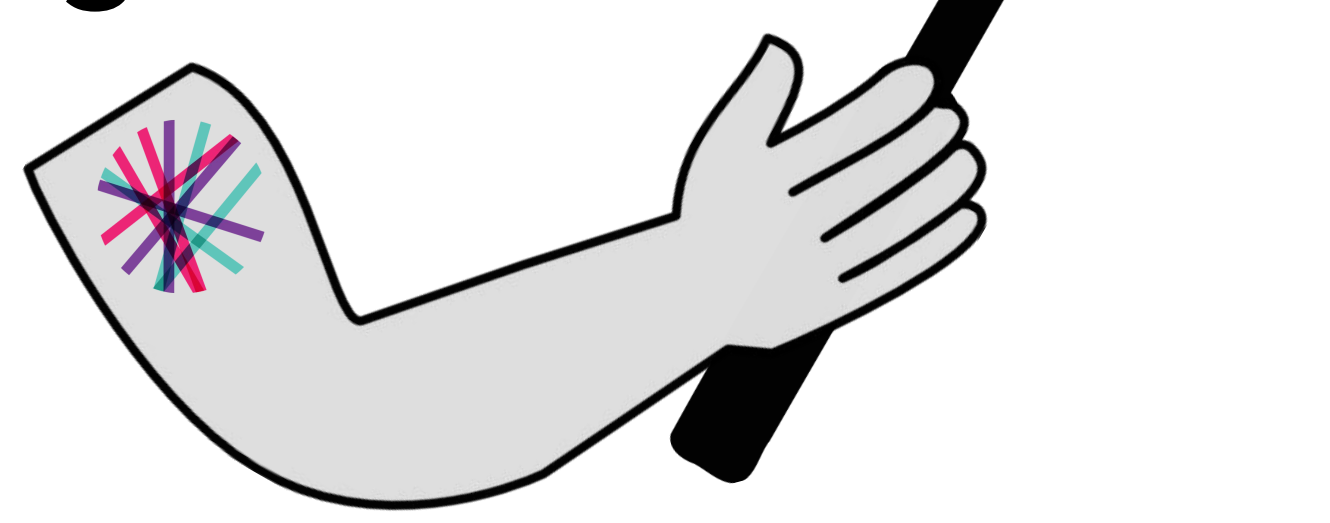




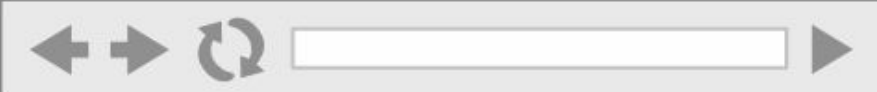

\section{Browser}

\section{Submission}

\section{Delivery}




\section{Commercial publishers \\ University presses}

Funders

Libraries

Tool providers

Authors

Collaborative I Community-driven 


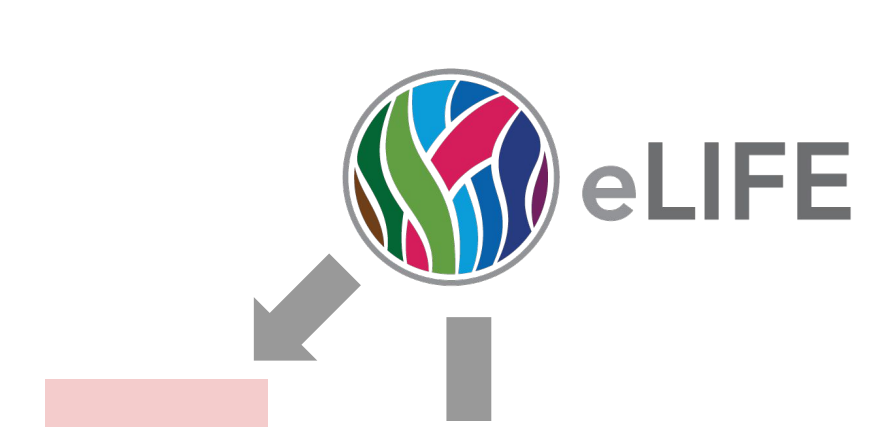

Libero

\section{Development}

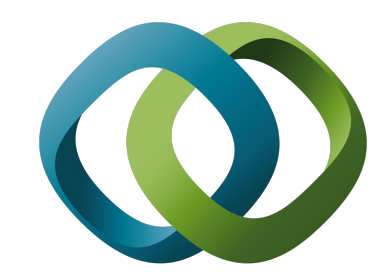

\section{Hindawi}

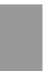

Development

\section{T collabras: Psychology}

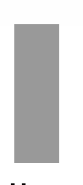

Feedback \& use cases

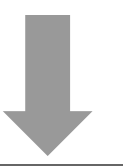

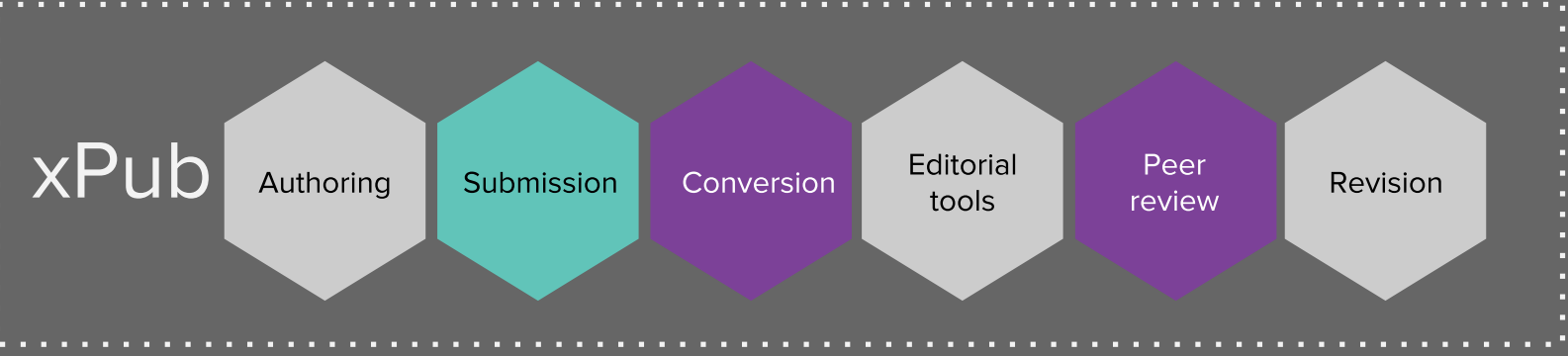

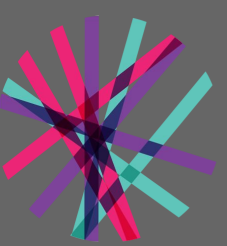

PubSweet Publishing Framework 


\section{xPub Community}

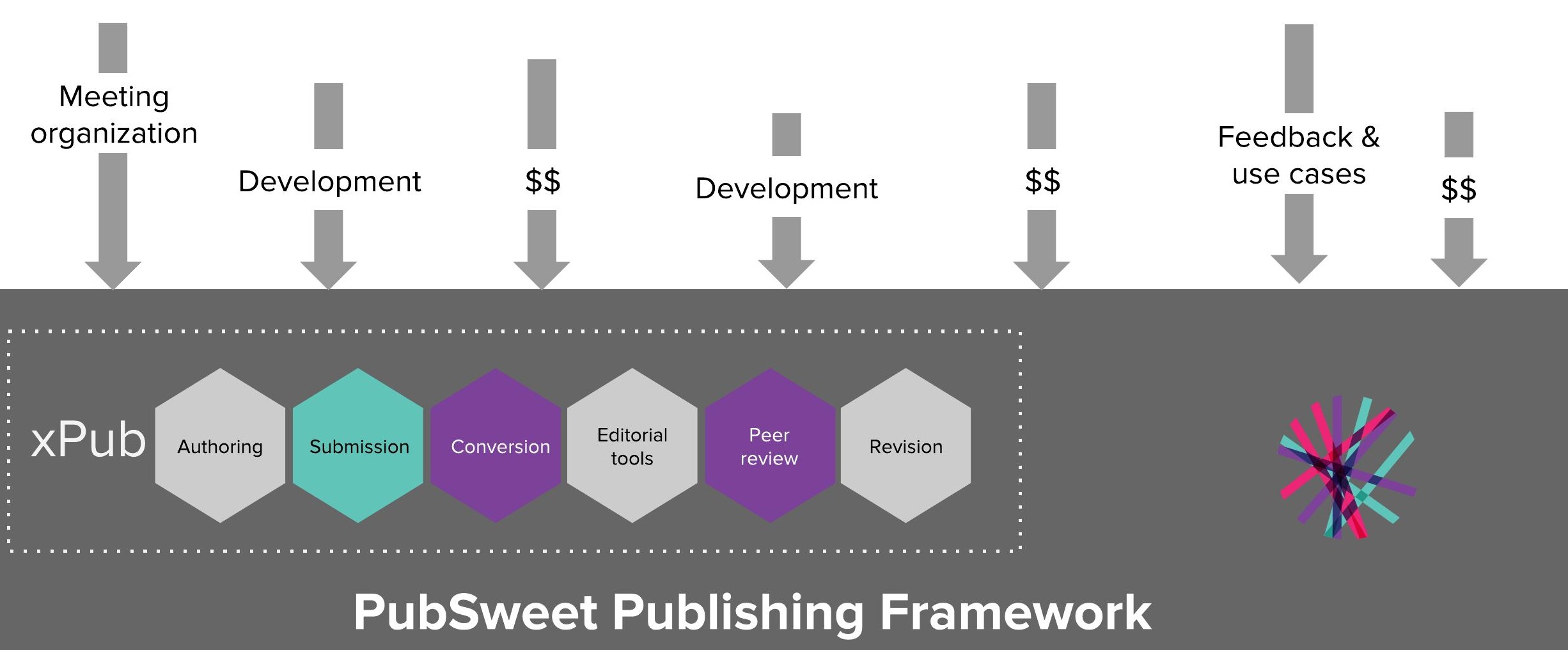



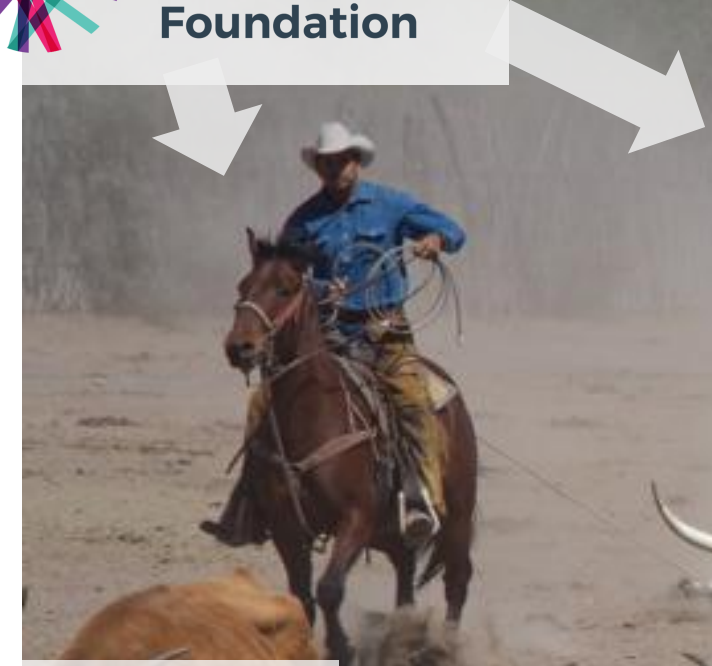

Authors

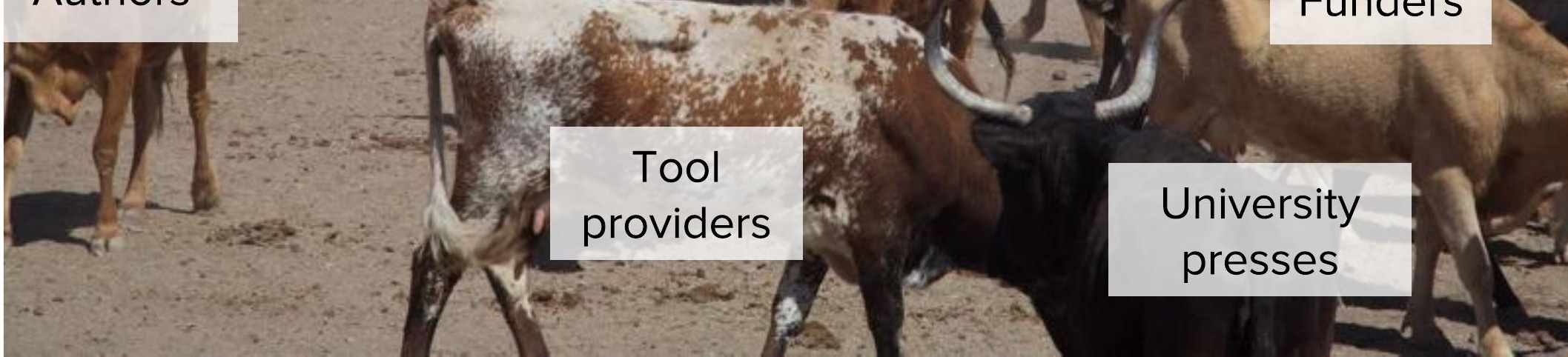

\section{Funders}

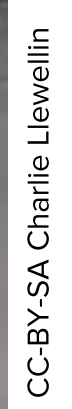

\section{Libraries}


Having other people build components to solve the problems you are facing is a great benefit of a common infrastructure.

...but also knowing that what you're building is useful to more than just your team really adds energy and purpose to our teams of developers and designers.

-Paul Shannon, eLife
An improvement for one becomes an improvement for all.

Individual communities can focus on core areas of expertise - peer review, hosting, discovery - knowing that their innovations will improve the entire system.

The result is more creativity, a more diverse set of solutions, and, ultimately, faster progress.

-Andrew Smeall, Hindawi 
A vision for scholarly communication

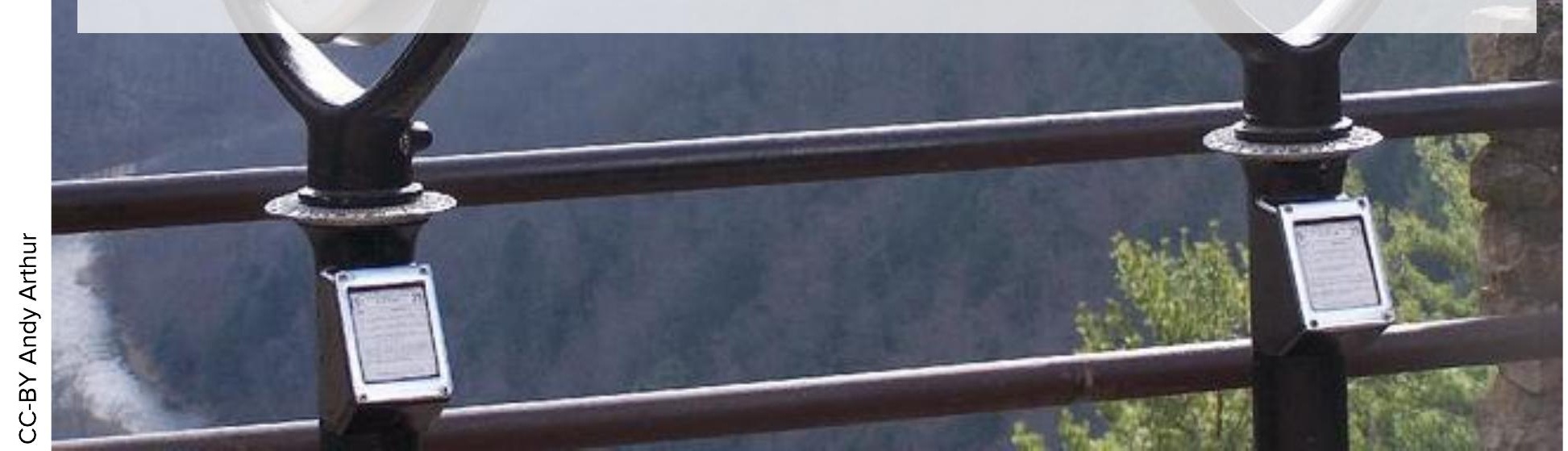




\section{The Open Ecosystem}

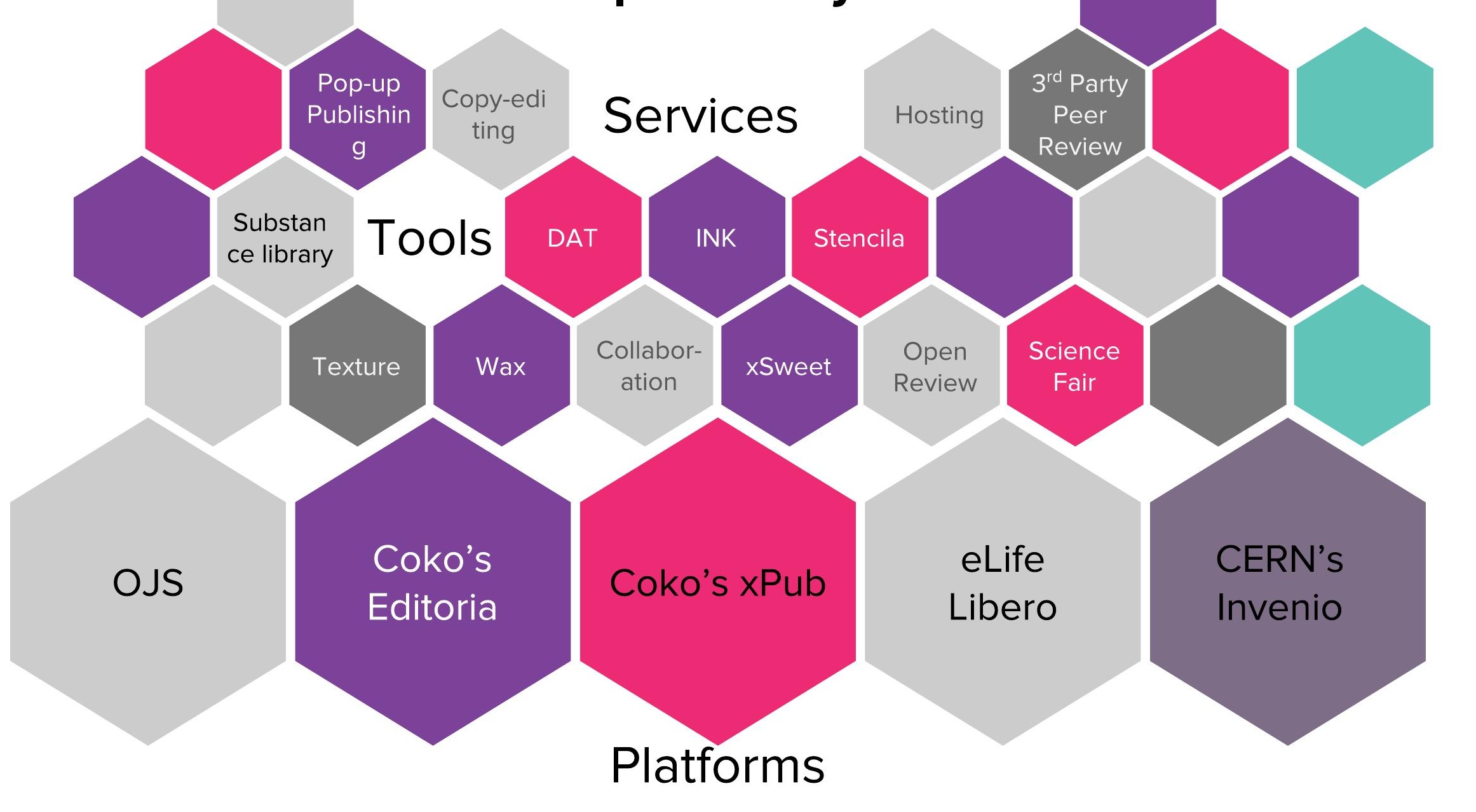




\section{Scholarly communication should be a public good}

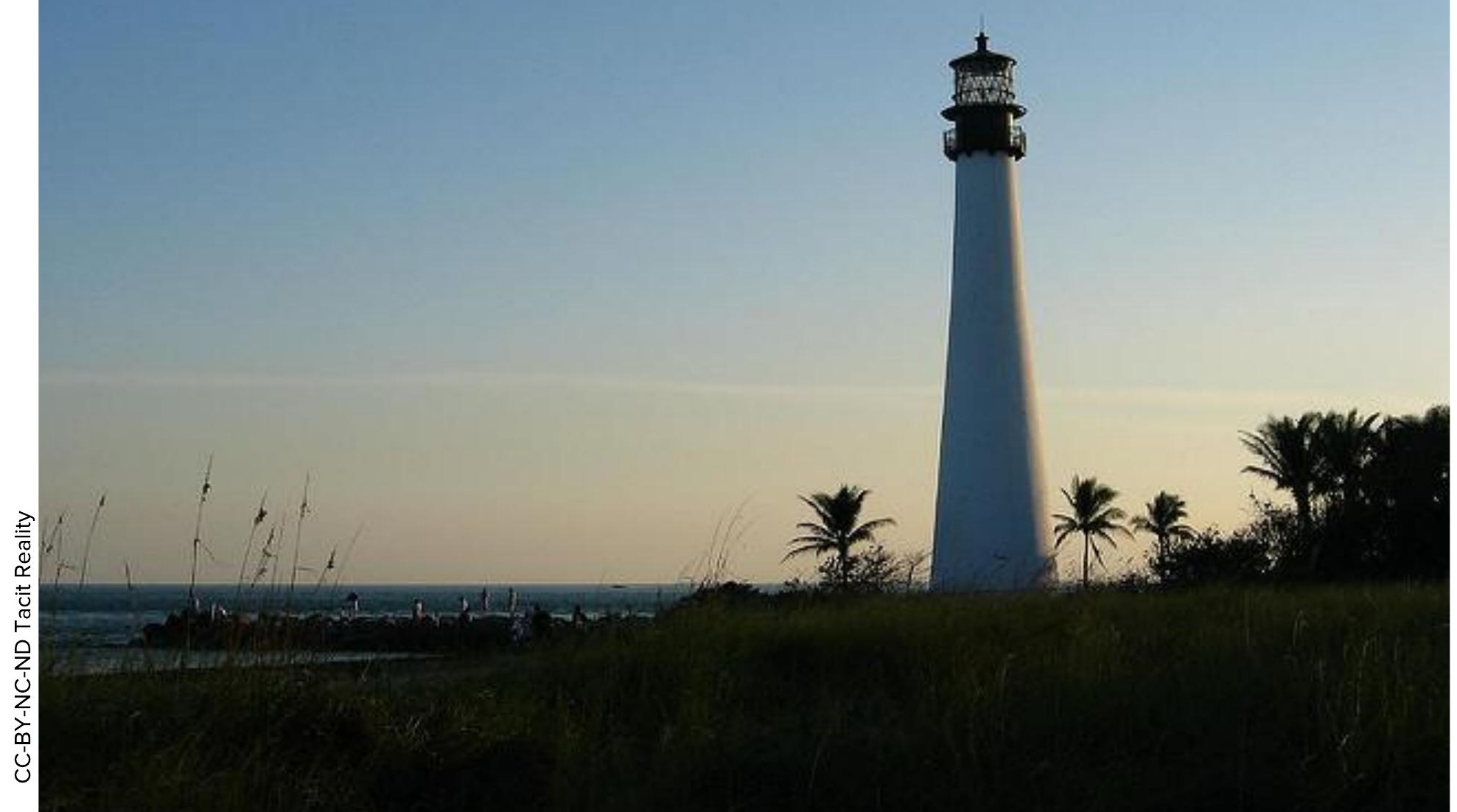


website

\section{email}

twitter

Coko carlystrasser.net carlystrasser@gmail.com @carlystrasser

coko.foundation

@cokofoundation

Tijaf MOONE 